

\section{Sumário}

EDITORIAL

Bruno Amaral Machado, Camilla de Magalhães Gomes e Soraia Mendes

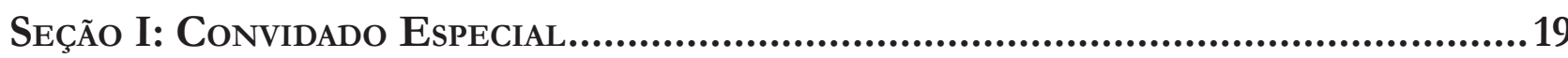

Autonomia Pessoal, Destino, julgamentos e instituições no Brasil: Notas Sobre uma PERGUNTA E ALGUMAS RESPOSTAS

Luiz Edson Fachin

SEÇÃo 2: Dossiê Temático....................................................................................40

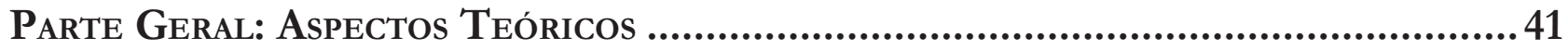

Raça e essencialismo na Teoria Feminista do Direito .......................................................43

Angela P. Harris, Tradução de Camilla de Magalhães Gomes e Ísis Aparecida Conceição

Políticas da morte: Covid-19 E Os Labirintos da Cidade Negra ........................................75

Ana Flauzina e Thula Pires

QUem PARIU AMÉFrica?: TRABALHO DOMÉSTICO, CONSTITUCIONALISMO E MEMÓRIA EM PRETUGUÊS

Juliana Araújo Lopes

O Lixo Vai Falar: Racismo, Sexismo e Invisibilidades do Sujeito Negro nas Narrativas de Direitos Humanos

Ciani Sueli das Neves

DiREITOS HUMANOS, DECOLONIALIDADE E FEMINISMO DECOLONIAL: FERRAMENTAS TEÓRICAS PARA A COMPREENSÃO DE RAÇA E GÊNERO NOS LOCAIS DE SUBALTERNIDADE

Rute Passos, Letícia Rocha Santos e Fran Espinoza

Direito, RAÇA E GÊNERO: ELEMENTOS PARA A CONSTRUÇÃo DE UMA TEORIA FEMINISTA DO DIREITO ADEQUADA AO FEMINISMO NEGRO

Mário Lúcio Garcez Calil e Debora Markman

"NeGras VAdiAs": A CRIMINALIZAÇÃo Do CORPO NEGRO QUE OUSA PROTESTAR.

Soraia da Rosa Mendes e Bruno Amaral Machado

A experiênCia do Abaetê Criolo como aÇão de enfrentamento a desigualdades de GÊNERO E RAÇA: UMA ANÁLISE DE DISCURSO SOBRE INTERSECCIONALIDADE

E FEMINISMO NEGRO

David Oliveira e Thalita Terto Costa 
ENTRE A AUSÊNCIA E O EXCESSO: A ATUAÇÃo DO ESTADO SOBRE CORPOS DISSIDENTES 230 Dayane do Carmo Barretos, Klelia Canabrava Aleixo e Vanessa de Sousa Soares

SILÊNCIOS E MITOS NUMA PERSPECTIVA INTERSECCIONAL: DO CONTROLE INFORMAL DE CORPOS AO CONTROLE PENAL DE MULHERES NEGRAS ......................................................248 Elaine Pimentel e Nathália Wanderley

Ministério Público e domínio Racial: poucas ilhas negras EM UM ARQuipélago nãoNEGRO 267

Saulo Murilo de Oliveira Mattos

Políticas públicas Para a ARTiCulaÇão de GÊNERo E RAÇA: MEIOS PARA GARANTir A REPRESENTATIVIDADE POLÍtiCA E JURÍDiCA DA MULHER NEGRA NO BRASIL 296 Mariana Dionísio de Andrade e Eduardo Régis Girão de Castro Pinto

Parte Específica: Incidências Concretas.......................................................... 317

REIMAGING THE POLICING OF GENDER VIOLENCE: LESSONS FROM WOMEN'S POLICE STATIONS IN Brasil AND ArgENTINA............................................................................................ 319 Kerry Carrington, Melissa Bull, Gisella Lopes Gomes Pinto Ferreira e María Victoria Puyol

NECROBIOPOLIÍtica DE GÊNERo No BRASIL CONTEMPORÂNEO: O FEMINICÍDIO EM TEMPOS DE FASCISMO SOCIAL 340 Maiquel Ângelo Dezordi Wermuth e Joice Graciele Nielsson

ViolÊNCIA CONTRA MULHERES QUILOMBOLAS: UMA REFLEXÃo SOBRE A APLICAÇÃo DE UMA PERSPECTIVA INTERSECCIONAL À LUZ DA IDEIA DE CONTRAPÚBLICOS SUBALTERNOS DELINEADA POR FRASER..... 360 Maria Eugenia Bunchaft, Leonardo Rabelo de Matos Silva e Gustavo Proença da Silva Mendonça

Políticas públicas de PREVEnÇÃo aO Feminicídio E INTERSECCIONALIDAdes . 384 Thiago Pierobom de Ávila, Marcela Novais Medeiros, Cátia Betânia Chagas, Elaine Novaes Vieira, Thais Quezado Soares Magalhães e Andrea Simoni de Zappa Passeto

DiREITO DE VIVER SEM VIOLÊNCIA: PROTEÇÃO E DESAFIOS DOS DIREITOS DAS MULHERES indígenas no Sistema InTERAmericano de Direitos Humanos Julia Natália Araújo Santos e Felipe Rodolfo de Carvalho

ANÁlise de GÊNERo E DE CRUZAMENTOS INTERSECCIONAIS DE UM PROGRAMA PARA AUTORES DE VIOLÊNCIA DOMÉSTICA CONTRA AS MULHERES

Mariana Fernandes Távora, Dália Costa, Camilla de Magalhães Gomes e Adriano Beiras

Controle PENAL dA LOUCURA E DO GÊNERO: REFLEXÕES INTERSECCIONAIS SOBRE MULHERES EgRESSAS DA MEdidA DE SEgurANÇA No Rio DE JANEIRO. .468 Bruna Martins Costa e Luciana Boiteux 
ONDE ESTÃo NOSSOS DIREITOS? O CAMPO FEMINISTA DE GÊNERO BORDADO PELAS MULHERES ATINGIDAS POR BARRAGENS

Tchenna Fernandes Maso e Tchella Fernandes Maso

Os SEGREDOS EPISTÊMICOS DO DIREITO DO TRABALHO.

Flávia Souza Máximo Pereira e Pedro Augusto Gravatá Nicoli

Reforma trabalhista e desigualdade de GÊNERo no Brasil: uMa PERSPECTIVA JuRÍdicA E ECONÔMICA

Natalia Branco Lopes Krawczun, Magno Rogério Gomes e Solange de Cassia Inforzato de Souza

A COLONIALIDADE DO PODER NA PERSPECTIVA DA INTERSECCIONALIDADE DE RAÇA E GÊNERO: ANÁLISE DO CASO DAS EMPREGADAS DOMÉSTICAS NO BRASIL .565

Daphne de Emílio Circunde Vieira Andrade e Maria Cecília Máximo Teodoro

COMPETIÇÃO POLÍTICA E DESIGUALDADES DE GÊNERO NAS ELEIÇÕES PARA ASSEMBLEIAS ESTADUAIS EM 2018

Lígia Fabris Campos, Décio Vieira da Rocha, Leandro Molhano Ribeiro e Vitor Peixoto

DisCrit: os LIMITES DA INTERSECCIONALIDADE PARA PENSAR SOBRE A PESSOA NEGRA COM DEFICIÊNCIA

Philippe Oliveira de Almeida e Luana Adriano Araújo

SeÇão III: Temais GeraIS

La Corte Interamericana de Derechos Humanos. Hermenéutica del derecho al MEDIO AMBIENTE SANO, A LA IDENTIDAD CULTURAL Y A LA CONSULTA, A LA LUZ DE LA SENTENCIA “Lhaka Honhat (nUestra tierra) vs. Argentina” (2020)

Juan Jorge Faundes Peñafiel, Cristobal Carmona Caldera e Pedro Pablo Silva Sánchez

LA RESPUESTA INSTITUCIONAL FRENTE A LA TRATA DE PERSONAS EN EL ESTADO DE CHIHUAHUA.

UN ANÁLISIS DE POLÍTICA PÚBLICA .676 Martha Aurelia Dena Ornelas

Comunidades quilombolas, RaCismo e ideologia no discurso de JAIr Bolsonaro: estudo CRÍTICO DOS DISCURSOS POLÍTICO E JUDICIAL 700 Ricardo de Macedo Menna Barreto e Helena Mascarenhas Ferraz

O Princípio Geral da Boa Administração no Código do Procedimento Administrativo Português. Pistas de inVestigação. 724 Ana Melro 


\title{
Análise de gênero e de cruzamentos interseccionais de um programa para autores de violência doméstica contra as mulheres*
}

\author{
Intersectional gender analysis of a program \\ for domestic violence perpetrators against \\ women
}

\author{
Mariana Fernandes Távora** \\ Dália Costa*** \\ Camilla de Magalhães Gomes ${ }^{* * * *}$
}

Adriano Beiras *****

* Recebido em 29/05/2020

Aprovado em 16/09/2020

** Mestre em Família e Gênero pelo Instituto Superior de Ciências Sociais e Políticas da Universidade de Lisboa. Promotora de Justiça e Coordenadora dos Núcleos de Direitos Humanos (MPDFT). ORCID: (https://orcid.org/00000002-0299-7604).

E-mail: marianatavora@hotmail.com

*** Doutora em Sociologia da Família. Professora no Instituto Superior de Ciências Sociais (ISCSP) e Políticas da Universidade de Lisboa (ULisboa). Investigadora no CIEG- Centro Interdisciplinar de Estudos de Gênero (ULisboa). Coordenadora da Pós-graduação em Criminologia e Reinserção Social (ISCSP-ULisboa) e Coordenadora do Observatório de Violência da Amadora. ORCID: (https://orcid.org/00000001-5184-3487).

E-mail: daliacosta@iscsp.ulisboa.pt

**** Doutora em Direito, Estado e Constituição pela Universidade de Brasília (UnB) e mestre pelo Programa de Pós-Graduação em Direito da Universidade Federal do Espírito Santo. Professora Adjunta da Faculdade Nacional de Direito da Universidade Federal do Rio de Janeiro (UFRJ). ORCID: (https://orcid.org/0000-00016993-7289).E-mail: camillamaggo@gmail.com

***** Professor do Departamento e do Programa de Pós-Graduação em Psicologia da Universidade Federal de Santa Catarina (UFSC). Doutor Europeu em Psicologia Social pela Universidade Autônoma de Barcelona (UAB), Espanha. Pós-doutorado na UFSC (Bolsa PDJCNPq), Universidad de Granada, Espanha e University of Brighton, Reino Unido. Coordenador do Grupo de Pesquisa Margens/UFSC. Vice-coordenador do grupo de pesquisa do CNPq NPPJ- Núcleo de Pesquisa em Psicologia Jurídica. ORCID: (https://orcid.org/00000002-1388-9326).E-mail: adrianobeiras@ufsc.br

\section{Resumo}

Este artigo, valendo-se dos aportes da sociologia compreensiva, coloca em perspectiva um programa brasileiro para autores de violência (PAV), buscando compreender como seu modelo teórico é interpretado e colocado em prática pelos/as profissionais que o aplicam. As categorias gênero e interssecionalidade foram mobilizadas como ferramentas analíticas, permitindo examinar o caminho entre o modelo teórico do programa e sua passagem para o contexto. Os achados, por meio da análise crítica dos discursos dos/ as profissionais que aplicam referido programa, indicam estarmos perante intervenção assente numa perspetiva teórica de gênero, com objetivos pouco diretivos, usando metodologia psicoeducativa e com fortes relações com o sistema de justiça. Também se conclui que o programa mantém indefinidos o seu fim, métodos, procedimentos, e resultados esperados, favorecendo permeabilidade à ordem de gênero - patriarcal e promotora da reprodução de domínio masculino. Apesar disso, alguns/mas profissionais com formação nos estudos de gênero conseguem atuar na prevenção à violência de gênero contra as mulheres, por meio de práticas que questionam o sistema de justiça, o poder executivo do Distrito Federal e o próprio PAV, desenvolvendo ações resistentes com capacidade transformadora. A agência individual deriva para coletivos emergentes, com casos de profissionais que procuram contatos com outros/as por similitude na sua reflexão acerca de uma ordem de gênero sútil, mas que produz efeitos, a indicar potência na mobilização de grupos aparentemente marginais.

Palavras-chave: Gênero; Interseccionalidade; Programa para autores de violência; Violência de gênero contras as mulheres; Distrito Federal/Brasil. 


\section{Abstract}

This article, using contributions of comprehensive sociology, puts in perspective a Brazilian program for perpetrators of violence (PPV), looking forward to understand how its theoretical model is interpreted and put into practice by the professionals who apply it. The categories gender and intersectionality were used as analytical tools, allowing to examine the pathway between the theoretical model of the program and its passage to the context. The findings, that are based on critical analysis of the discourses of the professionals who apply this program, indicate that the interventions are based on a theoretical perspective of gender, with low-directive objectives, using psychoeducational methodology and that display a strong relationship with the justice system. It also points out that the program maintains undefined its objectivs, methods, procedures and expected results, favoring permeability to the order of gender - patriarchal and promoting male domain reproduction. Nevertheless, the prevention of gender violence against women is seeked by some professionals which are capacitated in gender studies, by performing practices that confront the justice system, the executive branch of the Federal District and the PPV itself, developing resistant actions with transformative capacity. The individual agency moves toward to emerging collectives, with cases of professionals who seek contacts with similar reflection on a useful gender order, but that produces effects, indicating potency in the mobilization of apparently marginal groups.

Keywords: Gender; Intersectionality; Program to perpetrators of violence; Gender-based violence against women; Federal District/Brazil.

\section{Introdução}

Estima-se que, no mundo, $35 \%$ das mulheres tenham sido vítimas de violência física e/ou sexual por parte de um parceiro íntimo ou por não parceiro sexual ${ }^{1}$. No Brasil, a cada dois segundos, uma mulher é vítima de violência física e verbal ${ }^{2}$. O Distrito Federal (DF), nos últimos dez anos, registrou crescimento de crimes violência doméstica (VD) contra a mulher, passando de 10.858 registros policiais no ano de 2010 para 16.549 em 20193. No contexto desse grave problema social, os programas para autores de violência contra a mulher $(\mathrm{PAV})^{4}$ fazem parte de uma resposta, que se pretende integrada, compreensiva e focada na prevenção ${ }^{5}$.

No Brasil, os PAV têm sido utilizados como estratégia mais ampla de promoção da igualdade de gênero, em especial após a edição, em 2006, da Lei n. ${ }^{\circ}$ 11.340, de 7 de agosto - Lei Maria da Penha (LMP), buscando mitigar os impactos da violência por meio de intervenções de longo prazo ${ }^{6}$. Pesquisa realizada entre os anos de 2015 e 2016 pela Organização Não Governamental CEPIA - Cidadania, Estudo, Pesquisa, Informação e Ação indicou que 10 capitais brasileiras apresentam algum tipo de iniciativa direcionada a autores de vio-

\footnotetext{
WHO. Global and regional estimates of violence against women: prevalence and health effects of intimate partner violence and non-partner sexual violence. Genebra: WHO, 2013. Disponível em: https://apps.who.int/iris/bitstream/handle/10665/85239/9789241564625_eng.pd f;jsessionid=29F28A24D42985B20FABE4F77D19275E?sequence=1. Acesso em: 16 maio 2020.

2 INSTITUTO MARIA DA PENHA. Relógios da Violência. Disponível em: http://www.relogiosdaviolencia.com.br/\#. Acesso em: 13 mar. 2020.

3 DISTRITO FEDERAL. Crimes de violência doméstica, segundo a Lei ñ 11.340/2006 - "Lei Maria da Penha" - comparativo do $1^{\circ}$ trimestre dos anos de 2019 e 2020, por Região Administrativa e acompanbamento dos últimos anos no Distrito Federal. Brasília: SESP-DF, 2020. Disponível em: http://www.ssp.df.gov.br/wp-conteudo/uploads/2017/11/An\%C3\%A1lise-FSP-016_2020-Viol\%C3\%AAnciaDom\%C3\%A9stica-no-DF.pdf . Acesso em: 9 mar. 2020.

4 DAY, A.; CHUNG, D.; O'LEARY, P. Programs for men who perpetrate domestic violence: an examination of the issues underlying the effectiveness of intervention programs. Journal of Family Violence, v. 24, n. 3, pp. 203-212, 2009.

5 COSTA, D. A evolução de políticas públicas em Portugal na área da violência doméstica. In: I. D. (coord.). Violência doméstica e de género: uma abordagem multidisciplinar. Lisboa: Pactor, 2018. pp. 123-156.

PASINATO, W.; MACHADO, A.; ÁVILA, T. P. Políticas públicas de prevenção à violência doméstica e familiar contra as mulheres. In: Pasinato, W.; Machado, A.; ÁVILA, T. P. Políticas públicas de prevenção à violência contra a mulher: direito, transdisciplinariedade \& pesquisas sociojurídicas. v. 6. Brasília; São Paulo: Fundação Escola; Marcial Pons, 2019.
} 
lência com potencial para atuar como mecanismo de prevenção à violência de gênero?

No DF, em 2003, teve início o Programa para Autores de Violência do Núcleo de Atendimento à Família e Autores de Violência Doméstica contra a Mulher (PAV do NAFAVD) ${ }^{8}$. Desde então, o referido programa foi objeto de pesquisas, com apreciações positivas e negativas relativamente aos seus resultados. Por exemplo, Monteiro ${ }^{9}$ concluiu que há um entrave teórico-metodológico no programa, uma vez que não foi possível verificar, na prática, a consecução de um dos seus objetivos, qual seja, a transformação de valores por meio de responsabilização, reflexão e educação. Já a pesquisa quantiqualitativa de Silva ${ }^{10}$ indicou que a atenção voltada para os homens autores de violência pode interferir, de forma positiva, na percepção masculina sobre a violência doméstica contra a mulher. Nothaft ${ }^{11}$ identificou que, na experiência de mulheres que permanecem com seus companheiros, as intervenções promovidas pelo PAV do NAFAVD se mostraram como política de prevenção a novas violências. Por outro lado, constatou que o serviço, ainda, carece de abordagem interseccional institucionalizada.

Essa divergência nos resultados pode estar associada ao fato de os PAV no Brasil estarem permeados por desafios, que, segundo Beiras, Nascimento e Incrocci ${ }^{12}$, estão agrupados em três dimensões: i) concepções culturais que modelam as relações de gênero a partir da opressão e marginalização de certos grupos, o que acaba por ser recrutado pelos/s profissionais e usuários dos PAV; ii) ausência de uma política nacional para os autores de violência ${ }^{13}$ que contemple os eixos da prevenção secundária e terciária, com base em uma perspectiva de gênero crítica, única com potencial para desconstrução da desigualdade de gênero; iii) barreiras relacionadas à origem epistemológica e metodológica dos PAV, que contribuem para intervenções desalinhadas da concepção dos PAV como parte das estratégias para prevenção à violência de gênero.

Além dos debates e desafios identificados, desconhecemos estudos, numa perspetiva de gênero, que avaliem o seu impacto. A propósito, Gondolf ${ }^{14}$ pontua a necessidade de a comunidade científica se voltar para a implementação de um programa antes de examinar se ele funciona. Consideramos, de acordo com Gondolf, ser tempo de compreender o PAV do NAFAVD, dando um passo cientificamente balizado para futuros estudos de avaliação do programa. Para além disso, a compreensão do PAV do NAFAVD pode instrumentar aportes para o desenho de uma política distrital e talvez nacional de referência voltada à prevenção à violência de gênero.

PITANGUY, J., \& BASTERD, L. L. Grupos reflexivos: notas sobre os desafios para a construção de responsabilização, redução de violência e efetividade de programas para homens autores de violência contra as mulheres. Em W. Pasinato, B. A. Machado, \& T. P. Ávila (coord.). Políticas públicas de prevenção à violência contra a mulher. Brasília; São Paulo: Fundação Escola; Marcial Pons Brasil. 2019. pp. 253- 274, 2019.

8 AGUIAR, L. H. Gênero e masculinidades: follow-up de uma intervenção com homens autores de violência conjugal. 2009.175 f. Dissertação (Mestrado em Psicologia) - Instituto de Psicologia, Universidade de Brasília, Brasília, 2009. Disponível em: http:// repositorio.unb.br/bitstream/10482/8188/1/2009_LuizHenriqueMachadoAguiar.pdf. Acesso em: 28 maio 2020.

9 MONTEIRO, A. C. Autores de violência doméstica e familiar: um estudo sobre um grupo de reflexão no Paranoá/DF. 2014.183 f. Dissertação (Mestrado em Sociologia) - Departamento de Sociologia, Instituto de Ciências Sociais, Universidade de Brasília, Brasília, 2014.

10 SILVA, A. C. Violência por parceiro intimo: o acompanhamento ao homem autor da violência. 2016. 260 f. Tese (Doutorado em Saúde Coletiva) - Centro de Ciências da Saúde, Programa de Pós-graduação em Saúde Coletiva, Universidade Federal de Santa Catarina, Florianópolis, 2016.

11 NOTHAFT, R.J. Experiências de mulheres no enfrentamento da violência doméstica e familiar e suas relações com os serviços para autores de violência. Tese (Doutorado ao Programa de Pós-Graduação Interdisciplinar em Ciências Humanas). Universidade Federal de Santa Cantarina. Florianopólis, 2020.

12 BEIRAS, A.; NASCIMENTO, M.; INCROCCI, C. Grupos reflexivos: notas sobre os desafios para a construção de responsabilização, redução de violência e efetividade de programas para homens autores de violência contra as mulheres. In: PASINATO, W. B.; MACHADO, A.; ÁVILA, T. P. (coord.). Politicas públicas de prevenção à violência contra a mulher. Brasília; São Paulo: Fundação Escola; Marcial Pons Brasil. 2019. pp. 275-298.

13 AMADO, R. M. Os serviços de educação e responsabilização para bomens e autores de violência contra as mulheres: uma análise de quadros interpretativos, modelos de intervenção e atores. 2014. 87 f. Dissertação (Mestrado em Sociologia) - Faculdade de Economia, Universidade de Coimbra, Coimbra, 2014. Disponível em: https://core.ac.uk/download/pdf/43576976.pdf. Acesso em: 28 maio 2020.

14 GONDOLF, E. W. The weak evidence for batterer program alternatives. Aggression and Violent Behavior, v. 16, n. 4, pp. 347-353, jul./ago. 2011. 
Com base nessa proposta, que se assenta na sociologia compreensiva ${ }^{15}$, este artigo se propõe a responder, à luz de um quadro teórico dos estudos de gênero e intersceccionais, como o PAV do NAFAVD está organizado no plano teórico, como é interpretado e como é colocado em prática por seus/suas profissionais, com o objetivo de preparar estudos futuros dedicados à sua avaliação, contribuindo para o desenho de política públicas eficientes na prevenção à violência de gênero. Nessa proposta, mais descritiva, nossa hipótese é a de que, por influência de uma ordem de gênero, que se reproduz nas instituições ${ }^{16}$, no caso, a justiça e o poder executivo do DF, com reflexos nas representações e práticas profissionais, os objetivos iniciais do PAV do NAFAVD estejam a ser desvirtuados, por influência de prática profissionais que se sobrepõem. $\mathrm{O}$ problema emerge na permeabilidade das práticas profissionais a estereótipos, preconceitos e senso-comum, constrangendo os fins para os quais o PAV foi planejado no domínio das políticas públicas e no quadro legislativo. O contributo da Sociologia para aquelas áreas cientificas é de valor, quer quando se desenvolvem estudos de impacto de programas na população, quer, como se pretende neste artigo, quando se procuram compreender os programas de forma mais aprofundada do que a sua descrição acrítica permite. Além disso, é relevante também para estimular a autorreflexão dos/das profissionais que aplicam o PAV.

O artigo está organizado em quatro partes. Na primeira, são introduzidos os PAV, buscando, por meio de revisão bibliográfica nacional e estrangeira, identificar seus princípios gerais e padrões, a partir das categorias, dos aportes teóricos, dos objetivos e das metodologias utilizadas. Essa revisão servirá de referência ou padrão para se colocar o PAV do NAFAVD em perspectiva. Na segunda parte, os conceitos de gênero e interseccionalidade são operacionalizados, promovendo o seu uso como lente analítica do PAV do NAFAVD.

$\mathrm{Na}$ terceira, apresentamos a metodologia usada no estudo recentemente realizado no âmbito de uma dissertação de mestrado no programa X da Universidade X (AUTOR/A, 2019). Na quarta e última parte, procedemos a uma análise de dados, seguindo a técnica da análise crítica do discurso ${ }^{17}$, e à discussão de resultados.

\section{Os programas para autores de violência: fenômeno em construção}

Os Programas para Autores de Violência (PAV) encontram-se em um processo de amadurecimento, dentre os quais alguns estão sujeitos a pesquisas de avaliação de impacto ${ }^{18}$. Com início documentado nos anos 1980 desenvolveram-se sob diferentes perspectivas teóricas, com reflexos nas metodologias e nos objetivos adotados.

No que diz respeito às perspectivas teóricas, Stock ${ }^{19}$, referindo-se aos trabalhos de Adams (1990) e Hamberger y Hastings $(1993)^{20}$, identifica quatro modelos teóricos estruturantes dos programas para autores de VD: (i) modelo de orientação interior, que concebe a violência a partir de problemas psíquicos, fruto de experiências passadas; (ii) modelo de ventilação, interpretando a violência como responsabilidade do casal, sustentando, assim, o recurso a terapias de casal, sem prejuízo de tratamentos individuais; (iii) modelo sistêmico, que considera a violência entre o casal simétrica, centrando a ação sobre a interação entre os membros da família e destes com o contexto em que estão inseridos; e (iv) modelos sensíveis ao discurso de gênero, que incorporaram a visão crítica do movimento de mulheres sobre o sistema de justiça penal e introjetam a necessidade de introdução de programas para autores de VD nos planos de proteção à vítima.

\footnotetext{
15 JAHNKE, H. R. O conceito de compreensão na sociologia de Max Weber. Coimbra: Imprensa da Universidade de Coimbra, 2011. Disponível em: http://dx.doi.org/10.14195/978-989-260749-8. Acesso em: 28 maio 2020.

16 CONNELL, R.; PEARSE, R. Gênero, uma perspectiva global. Compreendendo o gênero - da esfera pessoal à política - no mundo contemporâneo. 3. ed. São Paulo: nVersos, 2015.

17 NOGUEIRA, C. A análise do discurso. In: ALMEIDA, L.; FERNANDES, E. Métodos e técnicas de avaliação: novos contributos para a prática e investigação. Braga: CEEP, 2001.

18 KELLY, L.; WESTMARLAND, N. Domestic violence perpetrator programmes: steps towards change. Project Mirabal Final Report. Londres; Durham: London Metropolitan University and Durham University, 2015.

19 STOCK, B. S. Violencia contra la mijer. Prevéncion. Programas de rehabilitácion, análisis internacional. Buenos Aires: BdeF, 2018.

20 A classificação dos referidos autores encontra-se em livros que só estão disponíveis em biblioteca de Manchester.
} 
$\mathrm{Na}$ literatura sobre os PAV, nota-se diversidade de metodologias ${ }^{21} 22{ }^{23} 24$. Ainda que díspares, grande parte das intervenções, conquanto recorram a abordagens da psicologia, não são consideradas psicoterapias, sem prejuízo de poderem surtir efeitos terapêuticos. Pode-se dizer que há predominância nos programas ao redor do mundo de abordagens psicoeducativas ou socioeducativas, calcadas em "modelos e valores de gênero hierarquizados como a causa principal do uso da violência contra a mulher" 2526 27, permitindo a desconstrução de valores aprendidos socialmente e a despatologização dos autores de violência.

Manita ${ }^{28}$ classifica os programas para autores de violência a partir da ligação entre objetivos e metodologia em que assentam. Assim, quando o programa tem feições psicoeducativas, os objetivos são amplos e almeja-se trabalhar a questão do poder, do controle/da dominação, as questões de gênero, as representações sociais, os mitos e os estereótipos sobre a violência, as dinâmicas abusivas, os efeitos da violência na vítima, a responsabilização pela violência praticada e as questões legais da violência doméstica contra a mulher. Já as intervenções de cariz psicoterapêutico visam a: (i) trabalhar motivações e processos associados às trajetórias de violência de cada indivíduo; (ii) conscientizar e responsabilizar pelos seus atos e pelas consequências dos seus atos sobre as vítimas - perceber a verdadeira extensão do abuso e dos danos/das consequências dos atos (e não manter o mito de que apenas a marca física determina a gravidade do mau trato), bem como não atribuir à vítima a culpa/responsabilidade pela violência exercida; (iii) transformar/eliminar do comportamento de controle e dominação, do comportamento agressivo, abusivo ou manipulador; e (iv) modificar o desenvolvimento de relações abusivas.

No Brasil, o desenvolvimento dos PAV está atrelado à edição da Lei n. ${ }^{\circ} 11.340$, de $2006^{29}$, conhecida como Lei Maria da Penha (LMP) ${ }^{30}$. A propósito, referida legislação foi alterada pela Lei n. ${ }^{\circ} 13.984$, de $2020^{31}$, que inseriu como medida protetiva de urgência a frequência do autor da violência a acompanhamentos psicossociais, por meio de atendimentos individuais e/ou em grupos de apoio. No entanto, até a presente data, não há uma política nacional para autores de VD, cujo reflexo é a existência, no Brasil, de um cenário

21 AMADO, R. M. Os serviços de educação e responsabilização para homens e autores de violência contra as mulheres: uma análise de quadros interpretativos, modelos de intervenção e atores. 2014. 87 f. Dissertação (Mestrado em Sociologia) - Faculdade de Economia, Universidade de Coimbra, Coimbra, 2014. Disponível em: https://core.ac.uk/download/pdf/43576976.pdf. Acesso em: 28 maio 2020. 22 BEIRAS, A.; CANTERA, L. M. Feminismo pós-estruturalista e masculinidades: contribuições para a intervenção com homens autores de violência contra a mulher. In: BLAY, E. A. (coord.). Feminismos e masculinidades: novos caminhos para enfrentar a violência contra a mulher. São Paulo: Cultura Acadêmica, 2014. pp. 29-44.

23 VELOSO, F. G.; NATIVIDADE, C. Metodologias de abordagem dos homens autores de violência contra as mulheres. In: LOPES, P. V.; LEITE, F. Atendimento a homens autores de violência doméstica: desafios à política pública. Rio de Janeiro: Instituto de Estudos da Religião, 2013. pp. 45-64.

24 BEIRAS, A.; BRONZ, A. Metodologia de grupos reflexivos de gênero. Rio de Janeiro: Instituto Noos, 2016. Disponível em: http:// noos.org.br/wp-content/uploads/2018/08/Metodologia-Noos_PDF-final.pdf. Acesso em: 22 maio 2020.

25 MANITA, C. A intervenção em agressores no contexto da violência doméstica em Portugal: estudo preliminar de caracterização. Lisboa: Comissão para Igualdade e para os Direitos da Mulher, 2005.

26 CEREJO, D. Intervenção com agressores em Portugal: características e caminhos de intervenção com agressores conjugais. In: NEVES, S.; COSTA, D. Violências de género. Lisboa: ISCSP-CIEG, 2017. p. 298.

27 TONELI, M. J.; BEIRAS, A.; CLIMACO, D.; LAGO, M. C. Por que pesquisar serviços destinados a homens autores de violência contra as mulheres? In: TONELI, M. J.; BEIRAS, A.; CLIMACO, D.; LAGO, M. C. Atendimento a bomens autores de violência contra as mulheres: experiências latino americanas. Florianópolis: UFSC/CFH/NUPPE, 2010. pp. 11-24.

28 MANITA, C. A intervenção em agressores no contexto da violência doméstica em Portugal: estudo preliminar de caracterização. Lisboa: Comissão para Igualdade e para os Direitos da Mulher, 2005.

29 BRASIL. Lei n. ${ }^{\circ}$ 11.340, de 7 de agosto de 2006. Portal da Legislação, Brasília, 2006. Disponível em: http:/ /www.planalto.gov.br/ ccivil_03/_Ato2004-2006/2006/Lei/L11340.htm. Acesso em: 28 maio 2020.

30 BEIRAS, A. Relatório mapeamento de serviços de atenção grupal a homens autores de violência doméstica contra mulheres no contexto brasileiro. Rio de Janeiro: Instituto Noos, 2014. Disponível em: http://www.noos.org.br/portal/wp-content/uploads/2015/04/RelatorioMapeamento-SHAV_site.pdf. Acesso em: 28 maio 2020.

31 BRASIL. Lei n. ${ }^{\circ}$ 13.984, de 3 de abril de 2020. Portal da Legislação, Brasília, 2020. Disponível em: http://www.in.gov.br/en/web/ dou/-/lei-n-13.984-de-3-de-abril-de-2020-251138826. Acesso em: 22 maio 2020. 
multiforme relativamente aos $\mathrm{PAV}^{32}{ }^{33}$.

Essa ausência de uma política nacional para os PAV é reflexo da não priorização no Brasil às alternativas penais. Relatório do Mecanismo Nacional de Prevenção e Combate à Tortura (MNPCT) ${ }^{34}$ refere que o investimento do Fundo Penitenciário Nacional foi repassado pelo Departamento Penitenciário Nacional (DEPEN) de forma homogênea para Estados e DF. Mais de 70\% dos recursos foram destinados à construção de estabelecimentos penais e, apenas, $0,17 \%$ do valor foi direcionado a "políticas de alternativas penais, monitoramento eletrônico, programas de educação e trabalho ou de apoio para volta à liberdade” (p. 135).

A seu turno, o privilégio de políticas carcerárias em detrimento de uma reinserção social vinculada a um estado de bem estar social mostra o quão distante estamos de um política criminal interseccional, ou seja, que deita um olhar para aquele/a que rompe com a norma penal a partir da relações operadas entre raça, classe e gênero ${ }^{35}$.

O PAV do NAFAVD é uma exceção ao cenário nacional, o que o torna central para reflexões sobre intervenções com autores de violência de gênero. Criado em 2003, permanece, desde então, como política pública do Governo do DF, vinculado à Secretaria da Mulher ${ }^{36}$, estando presente em nove regiões administrativas do DF. Os núcleos do NAFAVD funcionam, em grande parte, nas promotorias de justiça, por meio de termo de cooperação técnica firmado em 2012 com o Ministério Público do Distrito Federal e Territórios $(\mathrm{MPDFT})^{37}$. No âmbito das normativas distritais, o programa está inserido no I Plano Distrital de Políticas para as Mulheres de 2014/2015 ${ }^{38}$, que demonstrou a necessidade de que houvesse ampliação de unidades, o que, até a presente data, não ocorreu ${ }^{39}$.

\section{Gênero e interseccionalidade: ferramentas de análise crítica do PAV do NAFAVD}

Considerando-se que os PAV surgem como uma das respostas interventivas no enfrentamento da violência doméstica ${ }^{40}$ — uma das expressões da violência de gênero —, buscamos articular o conceito de gênero numa perspetiva interseccional.

Optamos, neste trabalho, pela proposta analítica de Scott ${ }^{41}$, conjugada com o modelo operacionalizado

\footnotetext{
32 AMADO, R. M. Os serviços de educação e responsabilização para homens e autores de violência contra as mulheres: uma análise de quadros interpretativos, modelos de intervenção e atores. 2014. 87 f. Dissertação (Mestrado em Sociologia) - Faculdade de Economia, Universidade de Coimbra, Coimbra, 2014. Disponível em: https://core.ac.uk/download/pdf/43576976.pdf. Acesso em: 28 maio 2020. 33 BEIRAS, A. Relatório mapeamento de serviços de atenção grupal a homens autores de violência doméstica contra mulheres no contexto brasileiro. Rio de Janeiro: Instituto Noos, 2014. Disponível em: http://www.noos.org.br/portal/wp-content/uploads/2015/04/RelatorioMapeamento-SHAV_site.pdf. Acesso em: 28 maio 2020.

34 BRASIL. Mecanismo Nacional de Prevenção e Combate à tortura (MNPCT). Relatório Anual 2017. 2018.

35 COLLINS, P.H; BILGE, S. Interseccionalidad. Madrid: Ediciones Morata, 2019.

36 DISTRITO FEDERAL. Secretaria de Estado da Mulher. Sobre a Secretaria. Disponível em: http://www.mulher.df.gov.br/ sedestmidh/. Acesso em: 31 maio 2019.

37 Informações extraídas de: DISTRITO FEDERAL. Secretaria de Estado da Mulher. Atendimento à Mulher. Núcleos de Atendimento à Família e aos Autores de Violência Doméstica. Disponível em: http://www.mulher.df.gov.br/nafavds/. Acesso em: 21 set. 2019.

38 DISTRITO FEDERAL. Secretaria de Estado da Mulher. I Plano Distrital de Políticas para as Mulheres 2014-2015. Brasília, 2014. Disponível em: http://www.mulher.df.gov.br/wp-conteudo/uploads/2017/11/I-Plano-Distrital-de-Pol\%C3\%ADticas-paraas-Mulheres.pdf. Acesso em: 28 maio 2020.

39 Informações extraídas de: MPDFT. Núcleo de Direitos Humanos. Núcleo de Gênero. Resumo executivo. Disponível em: http:// www.mpdft.mp.br/portal/pdf/noticias/maio_2019/RESUMO_EXECUTIVO.pdf . Acesso em: 21 set. 2019.

40 DAY, A.; CHUNG, D.; O’LEARY, P. Programs for men who perpetrate domestic violence: an examination of the issues underlying the effectiveness of intervention programs. Journal of Family Violence, v. 24, n. 3, pp. 203-212, 2009.

${ }^{41}$ SCOTT, J. Gênero: uma categoria útil de análise histórica. In: Holanda, H. B. Pensamento feminista: conceitos fundamentais. Rio de Janeiro: Bazar do tempo, 2019. pp. 49-80.
} 
por Connell e Pearse ${ }^{42}$, por entendermos que conferem ao gênero estatuto de categoria de análise, no qual se imbricam relações sociais e de poder, numa dinâmica entre estruturas sociais e atividades humanas ao longo do cotidiano e da história. Scott ${ }^{43}$ faz uso do gênero como categoria de análise, única com força para interrogar e transformar os paradigmas históricos existentes. A sua proposta assenta-se na interpelação do binarismo masculino/feminino, tendo como ponto de partida a história e a desconstrução dos termos da diferença sexual. Connell e Pearse ${ }^{44}$ apresentam um sistema representado por todas as relações de gênero ligadas a um plano estrutural — chamado ordem de gênero — e também ligadas a um plano micro, fomentado por práticas sociais — os regimes de gênero.

$\mathrm{Na}$ ordem de gênero, há um padrão que, conquanto nos pareça dado de forma natural, decorre de experiências construídas com base em uma imposição externa realizada por intermédio de normas sociais ou da pressão de autoridades (dimensão estrutural) que influenciam e, ao mesmo tempo, são dinamizadas por uma construção pessoal (dimensão relacional). Constitui-se num esquema estrutural não fixo influenciado por quatro dimensões relacionais que interagem entre si: as relações de poder, a divisão sexual do trabalho, as relações emocionais (cathexis) e as relações simbólicas ${ }^{45}{ }^{46}$.

Na primeira dimensão, as relações de poder imanam, de forma cultural e histórica, as relações de gêne$\mathrm{ro}^{47}$. Por exemplo, o direito gera ou encobre mecanismos de poder, incentiva, perpetua ou tolera hierarquias discriminatórias ${ }^{48}$, por meio de discursos falocêntricos ${ }^{49}$, podendo, assim, funcionar como barreira aos desafios à ordem de gênero, tal qual se pretende ao realizar os PAV.

A dimensão divisão sexual do trabalho decorre de uma "base estrutural da ordem de gênero do capitalismo moderno", que marca, profundamente, as noções de masculinidades e feminilidades ${ }^{50}$. No caso do PAV, é importante refletir sobre a permanência de uma divisão sexual do trabalho, que produz empecilhos para que homens trabalhem questões de gênero.

$\mathrm{Na}$ dimensão cathexis, estão as relações emocionais e sexuais construídas com base no gênero ${ }^{51}$, implicando a reflexão sobre uma ordem de gênero orientada para um padrão hegemônico de atração sexual com uma ordem heterormativa, que envolve um homem e uma mulher. No âmbito do PAV do NAFAVD, importa problematizar se as práticas profissionais se têm constituído em ethos restrito a: (i) relações heterossexuais a partir de um ideal heteronormativo; (ii) relações de conjugalidade ou equiparadas em que o homem é agressor e a mulher vítima, reproduzindo papéis sociais de gênero assentes no binarismo entre um dominador e uma dominada.

42 CONNELL, R.; PEARSE, R. Gênero, uma perspectiva global. Compreendendo o gênero - da esfera pessoal à política - no mundo contemporâneo. 3. ed. São Paulo: nVersos, 2015.

43 SCOTT, J. Gênero: uma categoria útil de análise histórica. In: Holanda, H. B. Pensamento feminista: conceitos fundamentais. Rio de Janeiro: Bazar do tempo, 2019. pp. 49-80.

44 CONNELL, R.; PEARSE, R. Gênero, uma perspectiva global. Compreendendo o gênero - da esfera pessoal à política - no mundo contemporâneo. 3. ed. São Paulo: nVersos, 2015.

45 CASACA, S. F. Revisitando as teorias sobre a divisão sexual do trabalho. Working Paper SOCIUS, Lisboa, n. 4, 2009. Disponível em: https://www.repository.utl.pt/bitstream/10400.5/1116/1/WP_4_2009.ultima.versao.pdf. Acesso em: 28 maio 2020.

46 CONNELL, R.; PEARSE, R. Gênero, uma perspectiva global. Compreendendo o gênero - da esfera pessoal à política - no mundo contemporâneo. 3. ed. São Paulo: nVersos, 2015.

47 CASACA, S. F. Revisitando as teorias sobre a divisão sexual do trabalho. Working Paper SOCIUS, Lisboa, n. 4, 2009. Disponível em: https://www.repository.utl.pt/bitstream/10400.5/1116/1/WP_4_2009.ultima.versao.pdf. Acesso em: 28 maio 2020.

48 BELEZA, T. P. Anjos e monstros: a construção das relações de género no Direito Penal. Ex aequo, n. 10, pp. 29-40, 2004.

49 CASALEIRO, P. O poder do direito e o poder do feminismo: revisão crítica da proposta teórica de Carol Smart. Ex aequo, n. 29, pp. 39-53, 2014.

50 CONNELL, R.; PEARSE, R. Gênero, uma perspectiva global. Compreendendo o gênero - da esfera pessoal à política - no mundo contemporâneo. 3. ed. São Paulo: nVersos, 2015. p. 165.

51 CASACA, S. F. Revisitando as teorias sobre a divisão sexual do trabalho. Working Paper SOCIUS, Lisboa, n. 4, 2009. Disponível em: https://www.repository.utl.pt/bitstream/10400.5/1116/1/WP_4_2009.ultima.versao.pdf. Acesso em: 28 maio 2020. 
No simbolismo, inserem-se relações produzidas com base na linguagem, da imagem e de artefatos (tecnologia $^{52}$, com as relações de gênero a serem condicionadas pelas interpretações do mundo. Importam os significados de gênero, como os acionados quando pensamos em mulher e homem e que, por sua vez, ativam "um imenso sistema de entendimentos, implicações, sobre tons e alusões que se acumularam ao longo da nossa história cultural"

As quatro dimensões estruturais da ordem de gênero têm tendência à crise provocada por forças sociais e por influências internas de transformação, na interação com outras dinâmicas da vida social ${ }^{54}$. Para além disso, essas estruturas de gênero entrelaçam-se com outras estruturas sociais. Por exemplo, no espectro da categoria "homens", o sistema de gênero está atravessado por classe, raça, diferenças nacionais, regionais e geracionais ${ }^{55}$.

O gênero como categoria analítica ${ }^{56}$ e ferramenta de análise ${ }^{57}$ se intersecciona com outras categorias, como raça, classe, idade, fazendo com que as especificidades de ser mulher, jovem, raça negra, sejam consideradas, permitindo que as diferenças possam ser abordadas dentro da diferença. É o que Crenshaw ${ }^{58}$ cunhou de interseccionalidade, mas que já havia sido objeto de estudos acadêmicos e práticas feministas desde os anos 1960 e 1970, sem essa nomenclatura, pelos feminismos negros ${ }^{59}$. Importante resgatar que, no âmago das teorizações interseccionais, estão as questões raciais e, nesse sentido, ganha centralidade o manejo engajado da interseccionalidade, ou seja, dentro dos propósitos de justiça social, liberdade e equidade ${ }^{60}$.

No âmbito da Teoria da Interseccionalidade, as alemãs Degele e Winker (2007, 2008, 2009, como referido em Mattos $^{61}$ ) identificam como importante procurar as possíveis interseções em três níveis: estrutural, identitário e das representações simbólicas, com o objetivo de contextualizar as categorias de diferenciação. As autoras procuram articular a interação entre estrutura e agência, sem tomar certas categorias a priori. No estrutural, partem do pressuposto de que gênero, classe, raça e corpo "predeterminam, de forma significativa, o acesso ao mercado de trabalho e às posições de mercado de trabalho" ${ }^{62}$. Nos níveis identitário e representacional, realçam que há ampliação das categorias de diferenciação. Além disso, as categorias identitárias são construídas com base na dissociação e da exclusão com/dos outros (masculino/feminino etc.), e, por isso, encontram-se num plano aberto, sujeito a reduções e ampliações na passagem para o concreto, campo em que se formam as representações. Assim defendem que, para identificação de categorias, sejam as que reproduzem, sejam as produtoras de novas estruturas sociais, é preciso examinar as práticas sociais, o que

\footnotetext{
52 CASACA, S. F. Revisitando as teorias sobre a divisão sexual do trabalho. Working Paper SOCIUS, Lisboa, n. 4, 2009. Disponível em: https://www.repository.utl.pt/bitstream/10400.5/1116/1/WP_4_2009.ultima.versao.pdf. Acesso em: 28 maio 2020.

53 CONNELL, R.; PEARSE, R. Gênero, uma perspectiva global. Compreendendo o gênero - da esfera pessoal à política - no mundo contemporâneo. 3. ed. São Paulo: nVersos, 2015. p. 72.

54 CONNELL, R.; PEARSE, R. Gênero, uma perspectiva global. Compreendendo o gênero - da esfera pessoal à política - no mundo contemporâneo. 3. ed. São Paulo: nVersos, 2015.

55 CONNELL, R. Gênero em termos globais. 1. ed. São Paulo: nVersos, 2016.

56 SCOTT, J. Gênero: uma categoria útil de análise histórica. In: Holanda, H. B. Pensamento feminista: conceitos fundamentais. Rio de Janeiro: Bazar do tempo, 2019. pp. 49-80.

57 CONNELL, R.; PEARSE, R. Gênero, uma perspectiva global. Compreendendo o gênero - da esfera pessoal à política - no mundo contemporâneo. 3. ed. São Paulo: nVersos, 2015.

58 CRENSHAW, K. Demarginalizing the intersection of race and sex: a black feminist critique of antidiscrimination doctrine, feminist theory and antiracist politics. The University of Chicago Legal Forum, v. 1, n. 8, pp. 139-167, 1989. Disponível em: http:// chicagounbound.uchicago.edu/uclf/vol1989/iss1/8. Acesso em: 28 maio 2020.

59 COLLINS, P. H. Se perdeu na tradução? Feminismo negro, interseccionalidade e política emancipatória. Revista Parágrafo, v. 5 , n. 1, pp. 6-17, jan./jun. 2017.

60 COLLINS, P. H. Se perdeu na tradução? Feminismo negro, interseccionalidade e política emancipatória. Revista Parágrafo, v. 5 , n. 1, pp. 6-17, jan./jun. 2017.

${ }^{61}$ MATTOS, P. As abordagens da "sociologia disposicional" e da "interseccionalidade": articulando uma proposta para os estudos de gênero. In: BODEMER, K. Cultura, sociedad y democracia en América Latina. Espanha: Iberoamericana Editorial Vervuert, 2012. pp. 251-270.

62 MATTOS, P. As abordagens da "sociologia disposicional" e da "interseccionalidade": articulando uma proposta para os estudos de gênero. In: BODEMER, K. Cultura, sociedad y democracia en América Latina. Espanha: Iberoamericana Editorial Vervuert, 2012. p. 252.
} 
somente é viável por meio da pesquisa empírica.

Conduziremos a análise do PAV do NAFAVD a partir da proposta de Degele e Winker (2007, 2008, 2009, como referido em Mattos, 2012 ${ }^{63}$, por também permitir recordar que, no caso brasileiro, a intersecção da raça é um meio de examinar o que a "colonialidade do gênero apagou, destruiu ou invisibilizou"

\section{Opções metodológicas: um olhar compreensivo sobre o PAV do NAFAVD}

Neste tópico, introduzimos a sociologia compreensiva como âncora que permite entender as experiências e os sentidos da ação social com base nos atores e das atrizes no nível de suas interações quotidianas ${ }^{65}$ ${ }^{66}$, num processo de interpretação que parte da confrontação do comportamento (as práticas profissionais) com um tipo ideal, que, na aceção de Weber, é o estudo de aspectos da vida social, selecionados pelo/a investigador/a e utilizados para observar a realidade ${ }^{67}$.

Os sujeitos considerados como mais bem posicionados para ajudarem a compreender o PAV do NAFAVD são aqueles/as que aplicam os programas — servidores/as públicos. Não tendo estado envolvidos/as nos processos de definição das bases teóricas e dos métodos de aplicação dos programas, constroem-nos e reconstroem-nos continuamente, por meio da sua aplicação empírica e rotineira. Essa ação transforma os PAV, seja ela mais ou menos crítica e mais ou menos informada - quer do ponto de vista dos conhecimentos teóricos de gênero, quer do ponto de vista das desigualdades reforçadas por diferenças de gênero intercetadas por outros marcadores. Assim, os/as servidores/as do PAV do NAFAVD "longe de serem recetores passivos, pensam por si mesmos, produzem e comunicam incessantemente suas próprias e específicas representações e soluções às questões que eles mesmos colocam" ${ }^{\text {. }}$.

Para alcançar o objetivo de compreender o PAV do NAFAVD (no plano teórico), como é interpretado (no plano das representações sociais ${ }^{69}$ ) e como é aplicado (no plano das práticas profissionais), recorremos à entrevista estruturada autoadministrada, num primeiro momento, e depois a entrevistas semiestruturadas, para aprofundar determinados aspectos e suscitar a autorreflexividade, nem sempre espontânea.

A opção pela entrevista estruturada autoadministrada justifica-se pela distância física, à época da recolha de dados, entre entrevistadora (em Lisboa, Portugal) e sujeitos de pesquisa (no DF, Brasil) e pela importância de definir, inicialmente, parâmetros de comparação entre respostas — o que é favorecido pela definição prévia de questões e respetivas categorias de resposta. Na fase seguinte, recorreu-se à entrevista semiestruturada aos mesmos sujeitos, porquanto trata-se de técnica que, comparativamente a outras, permite a "análise

\footnotetext{
63 MATTOS, P. As abordagens da "sociologia disposicional" e da "interseccionalidade": articulando uma proposta para os estudos de gênero. In: BODEMER, K. Cultura, sociedad y democracia en América Latina. Espanha: Iberoamericana Editorial Vervuert, 2012. pp. 251-270.

${ }^{64}$ GOMES, C. M. Gênero como categoria de análise decolonial. Civitas, v. 18, n. 1, p. 77, 2018. Disponível em: http://dx.doi. org/10.15448/1984-7289.2018.1.28209. Acesso em: 28 maio 2020.

${ }_{65}$ GUERRA, I. C. Pesquisa qualitativa e análise de conteńdo: sentidos e formas de uso. 1. ed. Estoril: Principia, 2006.

66 KAUFMANN, J.-C. A entrevista compreensiva - um guia para pesquisa de campo. 3. ed. (T. d. Abreu, \& L. Florencio, Trads.) Petropólis, RJ: Vozes. 2013.

JAHNKE, H. R. O conceito de compreensão na sociologia de Max Weber. Coimbra: Imprensa da Universidade de Coimbra, 2011. Disponível em: http://dx.doi.org/10.14195/978-989-260749-8. Acesso em: 28 maio 2020.

68 MOSCOVICI, S. Representacões sociais: investigações em psicologia social. 11. ed. Petrópolis: Vozes, 2015. p. 45.

69 Recorremos à teoria das representações sociais para aceder ao modo como os/as profissionais do NAFAVD interpretam o PAV. Vide: (i) JODELET, D. Réflexions sur le traitement de la notion de représentation sociale en psychologie sociale. Comunication. Information Médias Théories, v. 6, n. 2-3, pp. 14-41, 1984. Disponível em: https://www.persee.fr/doc/comin_1189-3788_1984_ num_6_2_1284. Acesso em: 28 maio 2020; (ii) VALA, J. Representações sociais e psicologia social do conhecimento cotidiano. In:VALA, J.; MONTEIRO, M. B. Psicologia social. 5 ed. Lisboa: Fundação Calouste Gulbekian, 2002. pp. 457-502.; (iii) PORTO, M. S. Crenças, valores e representações sociais da violência. Sociologias, Porto Alegre, a. 8, n. 16, pp. 250-273, jul./dez. 2006; e (iv) MOSCOVICI, S. Representações sociais: investigações em psicologia social. 11. ed. Petrópolis: Vozes, 2015.
} 
do sentido que os atores dão às suas práticas e aos acontecimentos com os quais se vêm confrontados" ${ }^{\text {"70 }}$. A amostragem teórica, com seleção intencional dos sujeitos, "convenientemente selecionada no universo (população) eleito" "71 não é representativa nem pretende sê-lo.

Na data da recolha de dados (entre novembro de 2018 e fevereiro de 2019), o DF tinha 9 núcleos do NAFAVD (universo ou população), razão pela qual escolhemos um/uma profissional de cada núcleo, bem como um sujeito que tenha participado da implementação do PAV do NAVAVD. Não se logrou contatar profissional de um dos 9 núcleos, sendo realizadas entrevistas estruturadas autoadministradas a profissionais de 8 núcleos e a 1 profissional que participou da implementação do PAV do NAFAVD e atualmente não mais o aplica. Na sequência, selecionamos uma amostra de 7 profissionais para as entrevistas semiestruturadas, pelos seguintes motivos: um dos sujeitos não estava disponível à data da recolha de dados e o outro não satisfazia os critérios definidos (aplicar o PAV do NAFAVD à época da recolha de dados).

A opção por esse tipo de amostragem permite, precisamente, encontrar "sujeitos socialmente significativos" "72, "pessoas mais ou menos típicas da categoria em estudo, que vivam determinada situação particular" "3. O principal limite dessa opção é a inviabilidade de generalizar os resultados obtidos, reconhecendo, portanto, que os discursos são situados, no sistema de justiça, no início do ano 2019, no DF.

Os critérios de seleção dos/das participantes, que permitiram incluí-los na amostra, são não cumulativos, designadamente: (i) desempenho de cargo de chefia e/ou coordenação do NAFAVD; (ii) experiência no atendimento, individual e grupal, a autores/as de violência contra as mulheres; e (iii) trajetória acadêmica na área dos estudos de gênero. Em específico, o terceiro critério visa a uma adequação ao propósito deste estudo — conhecer uma realidade a partir da ação social, à luz de um quadro teórico de gênero.

Começamos por pedir a colaboração de três informantes privilegiados/as, devido ao seu conhecimento acumulado, para com eles/as fazer o pré-teste do instrumento de recolha de dados (guião de entrevista). As suas respostas foram incluídas na análise porque as alterações introduzidas no guião não foram substantivas. As representações sociais e práticas profissionais dos/das sujeitos participantes no estudo $(\mathrm{N}=7)$ foram analisadas com base no que eles/as apresentaram por meio da produção dos seus discursos, implicando transcrição integral dos dados. O tratamento dos dados seguiu a proposta de análise crítica de discurso, guiada pelo que "está implícito e explícito nos diálogos que constituem a ação social"74.

As práticas discursivas devem ser entendidas como práticas sociais, que nascem de relações de poder concretas, num tempo delimitado, que indicam "certos efeitos que regulam e controlam a ordem social" 75 . Essa opção justifica-se por facilitar a criticidade da naturalização à hierarquia de gênero produzida pela sociedade. A análise crítica de discurso almeja o encontro de um discurso macro, que, por meio do indivíduo, revela os recursos sociais e culturais utilizados na atividade humana, o que nos interessa para atingir o objetivo deste estudo. Assim, foi feita a análise, atendendo a três aspectos: (i) a função do discurso, em que poder e conhecimento se conectam, pressupondo que as pessoas produzem discursos de resistência ou de regulação a depender de como se relacionam com as questões de poder e de sujeição; (ii) contradições, permitindo identificar significantes dominantes e dominados, e também processos de resistência; e (iii) a constituição das ideias, trazendo discursos que fogem ao nosso controle ${ }^{76}$.

\footnotetext{
70 QUIVY, R.; CAMPENHOUDT, L. Manual de investigação em ciências sociais. 7. ed. Lisboa: Gradiva, 2017. p. 193.

71 MARCONI, M., LAKATOS, E. M. Fundamentos da metodologia científica. 5. ed. São Paulo: Atlas, 2003. p. 163.

72 GUERRA, I. C. Pesquisa qualitativa e análise de conteńdo: sentidos e formas de uso. 1. ed. Estoril: Principia, 2006.

73 NOGUEIRA, C. A análise do discurso. In: ALMEIDA, L.; FERNANDES, E. Métodos e técnicas de avaliação: novos contributos para a prática e investigação. Braga: CEEP, 2001. p. 34.

74 NOGUEIRA, C. A análise do discurso. In: ALMEIDA, L.; FERNANDES, E. Métodos e técnicas de avaliação: novos contributos para a prática e investigação. Braga: CEEP, 2001. p. 22.

75 NOGUEIRA, C. A análise do discurso. In: ALMEIDA, L.; FERNANDES, E. Métodos e técnicas de avaliação: novos contributos para a prática e investigação. Braga: CEEP, 2001. p. 28.

76 NOGUEIRA, C. A análise do discurso. In: ALMEIDA, L.; FERNANDES, E. Métodos e técnicas de avaliação: novos contributos para a prática e investigação. Braga: CEEP, 2001.
} 


\section{Discussão de resultados: o pav do nafavd no discurso de suas atrizes e seus atores}

Apresentamos, doravante, os resultados, procurando apreender os modos pelos quais o modelo teórico do PAV do NAFAVD é interpretado pelos/as atores/atrizes, analisando, em seguida, como este se traduz em práticas profissionais, por meio do exame das ações de quem o pratica. Assim, estaremos mais bem apetrechados/as para aferir se o programa converge com as representações sociais de quem o aplica e onde se manifesta divergência entre representações e práticas, procurando, dessa forma, compreendê-lo.

5.1 Dimensões, categorias e indicadores do PAV do NAFAVD: construção de um modelo teórico a partir de um tipo ideal

Com base na literatura, construímos a tabela abaixo, com as dimensões, as categorias, as subcategorias e os indicadores dos PAV. O resultado que apresentamos é uma súmula de distintos programas, servindo de referência ou padrão a partir do qual se coloca em perspectiva o PAV do NAFAVD. O corpus de análise decorre dos dados recolhidos por meio da entrevista estruturada autoadministrada.

Tabela: modelo teórico dos PAV

\begin{tabular}{|c|l|l|}
\hline \multicolumn{2}{|c|}{ PROGRAMAS PARA AUTORES DE VIOLÊNCIA - PAV (objeto de estudo) } \\
\hline \multirow{4}{*}{ DIMENSÃO } & \multicolumn{1}{|c|}{ SUBCATEGORIA } & \multicolumn{1}{c|}{ INDICADOR } \\
\hline \multirow{4}{*}{$\begin{array}{c}\text { CARACTERIZAÇÃo } \\
\text { DOS PAV }\end{array}$} & Modelo de orientação interior & Violência a partir de problemas psíquicos \\
\cline { 2 - 3 } & Modelo de ventilação & Violência como responsabilidade do casal \\
\cline { 2 - 3 } & Modelo sistêmico & $\begin{array}{l}\text { Violência como produto das interações entre casal e o } \\
\text { meio }\end{array}$ \\
\cline { 2 - 3 } & Modelo sensível ao discurso de género & Violência interpretada à luz do género \\
\cline { 2 - 3 } & Socioeducativa ou psicoeducativa & $\begin{array}{l}\text { Transformações ou mudança assene em modelos } \\
\text { comportamentais, cognitivos, cognitivo- } \\
\text { comportamentais, humanistas e sistêmicos }\end{array}$ \\
\cline { 2 - 3 } & $\begin{array}{l}\text { Método de ação integrado com o sistema de } \\
\text { justiça/rede/formato grupal/objetivos } \\
\text { amplos/contextos reflexivos e dialógicos }\end{array}$ \\
\cline { 2 - 3 } & Objetivos amplos & Menos focado no autor \\
\cline { 2 - 3 } & Objetivos dirigidos & Mais dirigido ao comportamento do autor \\
\hline
\end{tabular}

Fonte: elaboração própria. ${ }^{77}$

No caso do DF, os discursos (escritos) dos/as 9 sujeitos que responderam às questões da entrevista autoadministrada revelam o uso de recursos linguísticos que remetem ao enquadramento da VD à luz das desigualdades de gênero, sugerindo, assim, que o PAV do NAFAVD assumiu, no plano teórico, modelo sensível ao gênero, que integra fatores de ordem macroestrutural nas manifestações de subalternidade feminina e violência contra as mulheres.

Em relação aos 9 entrevistados, 4 mencionam dispositivos legais baseados na concepção da violência doméstica e contra as mulheres como violência de gênero (por exemplo: The Convention on the Elimination of all Forms of Discrimination Against Women - CEDAW, Convenção de Belém do Pará, LMP), 5 fazem menção explícita à expressão "feminista", 3 a direitos humanos e 2 a marcadores como raça, gênero e classe social, o que nos permite considerar que, também, concebem a violência à luz das relações de gênero, deixando inferir que o PAV do NAFAVD foi concebido dentro do modelo sensível ao discurso de gênero, seguindo a

Elaborada com fundamento nas obras de Manita (2005), Amado (2014), Beiras (2014) e Stock (2018). 
tendência dos PAV no Brasil $^{78}$ e do contexto latino-americano ${ }^{79}$.

A metodologia psicoeducativa, uma das mais recorrentes na maior parte dos PAV, é marcada pelos seguintes indicadores: (i) integração com a rede; (ii) formato grupal; e (iii) técnicas reflexivas, reeducativas e dialógicas ${ }^{8081} 828384$ (Acosta, Andrade Filho \& Bronz, 2004), e emerge como preponderante no PAV do NAFAVD com base no discurso dos/as profissionais entrevistados/as.

A integração com a rede está presente, explicitamente, no discurso de 8 das/os 9 informantes, indicando que o PAV do NAFAVD se assenta numa lógica colaborativa entre agências que intervêm no fenômeno da violência doméstica contra a mulher. 5 informantes acentuam até mesmo a articulação a nível local. O/A informante 1 acrescenta um elemento importante ao se referir à ausência de protocolo entre o PAV do NAFAVD e os restantes elementos da rede de enfrentamento à VD, convergindo com a narrativa da/o informante 6 que, por sua vez, alude à falta de comunicação entre serviços, interpretando-a como necessária e favorável.

O segundo indicador — o formato grupal — é dominante pois, a respeito dos 9 informantes, 5 usam as expressões "grupos reflexivos" e 2, "grupos de homens", o que revela intervenção organizada em grupo com homens. De acordo com os informantes, os grupos são organizado com 10 a 15 homens.

Vale esclarecer que a expressão "grupos reflexivos" tem sido usada muitas vezes como sinônimo de grupos para homens autores de violência. Os grupos reflexivos derivam da metodologia desenvolvida pelo Instituto Noos, que valoriza a (auto)reflexão como forma de contextualizar a narrativa pessoal (do domínio do privado) nos temas propostos pelos/as profissionais que facilitam o grupo ${ }^{85} 86$. A seu turno, nem sempre grupos de homens incorporam técnicas reflexivas.

No caso do NAFAVD, o terceiro indicador revela que o PAV do NAFAVD utiliza técnicas reflexivas nos grupos que organiza, alocando no espaço grupal um espaço importante de troca de experiências ${ }^{88}$, numa dinâmica interacional. A referência ao uso de técnicas reflexivas emerge na narrativa de 8 das/os 9 informantes; 3 mencionam práticas reeducativas e 2 , técnicas dialógicas.

Algo que chama a atenção é a associação pelas/os 9 informantes da expressão psicossocial às expressões

\footnotetext{
78 BEIRAS, A. Relatório mapeamento de serviços de atenção grupal a homens autores de violência doméstica contra mulheres no contexto brasileiro. Rio de Janeiro: Instituto Noos, 2014. Disponível em: http://www.noos.org.br/portal/wp-content/uploads/2015/04/RelatorioMapeamento-SHAV_site.pdf. Acesso em: 28 maio 2020.

79 TONELI, M. J.; BEIRAS, A.; CLIMACO, D.; LAGO, M. C. Por que pesquisar serviços destinados a homens autores de violência contra as mulheres? In: TONELI, M. J.; BEIRAS, A.; CLIMACO, D.; LAGO, M. C. Atendimento a homens autores de violência contra as mulheres: experiências latino americanas. Florianópolis: UFSC/CFH/NUPPE, 2010. pp. 11-24.

80 MANITA, C. A intervenção em agressores no contexto da violência doméstica em Portugal: estudo preliminar de caracterização. Lisboa: Comissão para Igualdade e para os Direitos da Mulher, 2005.

81 ACOSTA, F.; BRONZ, A. Desafios para o trabalho com homens em situação de violência com suas parceiras íntimas. In: BLAY, E. A. (coord.). Feminismos e masculinidades: novos caminhos para enfrentar a violência contra a mulher. São Paulo: Cultura Acadêmica, 2014. pp. 139-148.

82 BEIRAS, A.; BRONZ, A. Metodologia de grupos reflexivos de gênero. Rio de Janeiro: Instituto Noos, 2016. Disponível em: http:// noos.org.br/wp-content/uploads/2018/08/Metodologia-Noos_PDF-final.pdf. Acesso em: 22 maio 2020.

83 STOCK, B. S. Violencia contra la mujer. Prevéncion. Programas de rehabilitácion, análisis internacional. Buenos Aires: BdeF, 2018.

84 ANTEZANA, A. P. Intervenção com homens que praticam violência contra seus cônjuges: reformulações teórico-conceituais para uma proposta de intervenção construtivista-narrativista com perspectiva de gênero. Nova Perspectiva Sistêmica, Rio de Janeiro, v. 21, n. 42, pp. 9-27, abr. 2012. Disponível em: https://www.revistanps.com.br/nps/article/view/121/96. Acesso em: 28 maio 2020. 85 ACOSTA, F; BRONZ, A. Desafios para o trabalho com homens em situação de violência com suas parceiras íntimas. In: BLAY, E. A. (coord.). Feminismos e masculinidades: novos caminhos para enfrentar a violência contra a mulher. São Paulo: Cultura Acadêmica, 2014. pp. 139-148.

86 BEIRAS, A.; BRONZ, A. Metodologia de grupos reflexivos de gênero. Rio de Janeiro: Instituto Noos, 2016. Disponível em: http:// noos.org.br/wp-content/uploads/2018/08/Metodologia-Noos_PDF-final.pdf. Acesso em: 22 maio 2020.

87 TONELI, M. J.; BEIRAS, A.; CLIMACO, D.; LAGO, M. C. Por que pesquisar serviços destinados a homens autores de violência contra as mulheres? In: TONELI, M. J.; BEIRAS, A.; CLIMACO, D.; LAGO, M. C. Atendimento a homens autores de violência contra as mulheres: experiências latino americanas. Florianópolis: UFSC/CFH/NUPPE, 2010. pp. 11-24.

88 LATTANZIO, F. F.; BARBOSA, R. R. Grupos de gênero nas intervenções com as violências masculinas: paradoxos de identidade, responsabilização e vias de abertura. In: LOPES, P. V.; LEITE, F. Atendimento a homens autores de violência doméstica: desafios à política pública. 1. ed. Rio de Janeiro: ISER, 2013. pp. 87-105.
} 
programa, acompanhamento e intervenção. Esse conteúdo psicossocial, muito marcado nos discursos, segundo os/as próprios/as informantes, se dá em razão de uma presença preponderante de profissionais das áreas de psicologia, serviço social e pedagogia. Dessa análise resulta, com clareza, que o PAV do NAFAVD assume uma metodologia psicoeducativa.

Quanto à equipe que faz o atendimento dos autores, as/os informantes deixam claro que se trata de uma dupla integrada por profissionais das áreas de assistência social, psicologia e pedagogia, embora outros/as profissionais possam integrar essa equipe. Apesar da composição da equipe, o discurso das/os profissionais sugere que a psicologia, o serviço social e a pedagogia são as áreas ligadas à intervenção psicossocial. Interessante notar que não há exigência quanto ao gênero dos/as profissionais, que são nomeados/as por concurso público. Sendo verdadeiro que as controvérsias sobre o gênero do/a profissional e o seu impacto nas reflexões provocadas em grupo não ganhou centralidade nas pesquisas científicas ${ }^{89}$; também é verdade que o debate está aberto e essa discussão aparece nos dados recolhidos, relacionada às resistências dos autores de violência no engajamento ao grupo.

Outro estudo teria de ser desenvolvido para dar conta dessa discussão, pois um detalhe que chama a atenção é, justamente, o gênero das equipes. Em relação aos 9 informantes, 7 são mulheres, o que evidencia que o PAV do NAFVAD também se comporta dentro de um processo de acumulação com base no gênero e produz (e reproduz) divisão sexual do trabalho ${ }^{90}$, com as profissões do cuidar mantendo-se, predominantemente, feminizadas.

Assim, importaria refletir aprofundadamente acerca de algumas questões: o PAV do NAFAVD, como programa que se constrói com recurso a profissões ligadas ao cuidado (psicologia, pedagogia e assistência social), locus historicamente feminino, acaba por se tornar um espaço pouco permeável à presença masculina nas equipes? Será que a tônica do cuidado influencia a visão para o programa e a feminização das equipes influencia as práticas profissionais? Será que a tônica do cuidado tem capacidade transformadora das relações de gênero? Será esse fato resultado da presumida neutralidade de gênero na esfera profissional, reforçando a ideia de que só às mulheres interessa discutir gênero e somente elas se envolvem na transformação das relações de gênero? Essas são perguntas que não terão resposta neste estudo, mas dele nascem e podem encetar futuras pesquisas.

Doravante examinamos os objetivos, partindo da literatura, que nos informa que programas com caráter psicoeducativo ou socioeducativo tendem a definir objetivos amplos e menos focados no autor, enquanto as metodologias psicoterapêuticas favorecem a definição de objetivos centrados nas motivações e processos associados às trajetórias de violência de cada indivíduo ${ }^{91}$.

O PAV do NAFAVD, nos discursos dos/das informantes, emerge como estruturado com objetivos amplos, voltados à reflexão sobre gênero, violência e direitos humanos, conscientização sobre a LMP e construção de técnicas de comunicação não violenta, apesar de 6 das/os 9 informantes, também, mencionarem o propósito de o autor da violência ser responsabilizado pela prática da violência contra a vítima.

Portanto, a partir dos discursos dos/das 9 servidores/as, o PAV do NAFAVD, no plano teórico: (i) assenta-se numa perspetiva teórica de gênero, compreendendo a VD como expressão da violência de gênero e contra as mulheres ${ }^{92}$, reconhecendo assimetrias nos capitais sociais e históricos da mulher ${ }^{93}$; (ii) privilegia

\footnotetext{
89 COSTA, D.; BAPTISTA, I. Relatório de investigação realizada na Equipa Lisboa Penal 5 da Direção Geral de Reinserção e Serviços Prisionais. Lisboa: ISCSP, 2019.

90 CONNELL, R.; PEARSE, R. Gênero, uma perspectiva global. Compreendendo o gênero - da esfera pessoal à política - no mundo contemporâneo. 3. ed. São Paulo: nVersos, 2015.

91 MANITA, C. A intervenção em agressores no contexto da violência doméstica em Portugal: estudo preliminar de caracterização. Lisboa: Comissão para Igualdade e para os Direitos da Mulher, 2005.

92 ALMEIDA, S. S. Essa violência mal-dita. In: ALMEIDA, S. S. Violência de gênero e políticas públicas. Rio de Janeiro: UFRJ, 2007. pp. 23-41.

${ }_{93}$ BANDEIRA, L. M. Violência de gênero: a construção de um campo teórico e de investigação. Revista Sociedade e Estado, Brasília,
} 
uma metodologia psicoeducativa para cumprir objetivos amplos (menos diretivos); (iii) assume um modelo integrado com o sistema de justiça, que se vale de equipes multidisciplinares, apesar de predominantemente com especialidade na áreas do psicossocial; utilizando-se de técnicas reflexivas num formato grupal.

\subsection{Entre representações e práticas profissionais: influências da ordem de gênero}

Aprofundando a análise para identificar as representações sociais transmitidas por meio do discurso (oral), incluindo pontos de vistas censurados ou mudos ${ }^{94}$, procuramos agora situar a origem dos conceitos mencionados pelos/as servidores/as quando tentam dotar o PAV de sentido, racionalizando-o para, por meio da linguagem, (re)construírem-no e, assim, torná-lo familiar ${ }^{95}$.

Ao serem instadas/os a refletir sobre a perspectiva teórica que guia a prática profissional quotidiana, 3 das/os 7 entrevistadas/os relembraram a origem do PAV, marcando-a como de base psicoterápica. A/O informante 7 destaca que, inicialmente, havia "um viés muito de psicoterapia".

A/O informante 1 adensa a reflexão ao referir que, ao longo do tempo, a perspectiva "psi" do PAV do NAFAVD passou a ser questionada, suscitando debates na equipe. Provavelmente a entrada em vigor da LMP, no terceiro ano do NAFAVD, suscitou reflexão ao trazer ao quotidiano das/os profissionais do PAV novo paradigma, consubstanciado no fato de a LMP tratar a VD contra a mulher como violência de gênero e alçá-la a uma violação de direitos humanos, como problema público, estrutural, multifatorial, isso é, descolado de patologias individuais ${ }^{96}$, e exigindo abordagens práticas compreensivas, no sentido de serem abrangentes ou holísticas. Na realidade, nas entrevistas, a LMP surge como marco delimitador da atuação dos profissionais. O discurso do/a informante 7 é muito explícito, ao mencionar que a LMP é sua baliza teórica, implicando trabalhar "com os homens os cinco tipos de violência previstas na lei.".

A interpretação do fenômeno da violência e os novos conceitos trazidos pela LMP, em específico o gênero, ganharam familiaridade e sedimentação entre os/as profissionais do NAFAVD por meio de ações formativas individuais e coletivas, cuja iniciativa não seguiu formato estruturado e destinado a esse fim, mas por interesse pessoal dos/das profissionais. Nesses espaços, encetou-se a ampliação do olhar sobre o fenômeno da violência, conforme ilustra o/a informante 7 ao mencionar que foi uma supervisão paga pela equipe que trouxe "o olhar do atendimento psicossocial e o olhar do gênero".

A fala do/da informante 7, que também encontra eco no discurso dos/as informantes 2 e 8 , evidencia uma reconstrução da origem "psi" do PAV do NAFAVD, passando a assumir uma perspetiva teórica de gênero. A LMP constituiu-se marco e origem da assimilação de recursos linguísticos, cujos reforço e sedimentação se deram por meio de capacitações da equipe. No entanto, conquanto o conceito de gênero apareça como fundante nas intervenções com os autores de violência, as ações quotidianas revelam que não há clareza sobre o que seria essa prática baseada no gênero. Como pondera a/o informante 2, "atender incorporando uma perspetiva de gênero não é dar uma aula sobre gênero." Acrescenta que as discussões sobre gênero estão centradas nos "papéis de gênero", dando-se pouca ênfase a "outras dimensões da desigualdade". A/O entrevistada/o 7 confirma-o, afirmando "se a gente for falar sobre papéis de gênero, estereótipos, é tranquilo, eu acho que todo mundo de alguma forma trabalha isso, (...), mas quando a gente discute relações de poder...", terminando o seu raciocínio com silêncio, a sugerir que discussões mais contundentes, que problematizam relações de poder entre homens e mulheres — e entre homens e entre mulheres — ainda

\footnotetext{
v. 29, n. 2, pp. 449-469, maio/ago. 2014.

94 GUERRA, I. C. Pesquisa qualitativa e análise de conteńdo: sentidos e formas de uso. 1. ed. Estoril: Principia, 2006.

95 VALA, J. Representações sociais e psicologia social do conhecimento cotidiano. In:VALA, J.; MONTEIRO, M. B. Psicologia social. 5 ed. Lisboa: Fundação Calouste Gulbekian, 2002. pp. 457-502.

96 COSTA, D. A intervenção em parceria na violência conjugal contra as mulheres: um modelo inovador? 2011. 395 f. Tese (Doutorado em Sociologia) - Universidade Aberta, Lisboa, 2011. Disponível em: https://repositorioaberto.uab.pt/handle/10400.2/1813. Acesso em: 28 maio 2020 .
} 
não permeiam toda a equipe.

A/O informante 5 também desvela práticas dissonantes da teoria ao mencionar que a perspetiva de gênero mais crítica com abordagem do homem não somente como "reprodutor da violência contra a mulheres", mas também no campo de masculinidades "marginalizadas", em que se produz o rechace à homossexualidade, não é "uma base geral do NAFAVD".

O trabalho com outros marcadores que produzem desigualdade, como o racismo, somente foi encontrado como tema na fala da/o informante 7. Por outro lado, quando traz à tona o tema das masculinidades, cinge-o ao âmbito da conjugalidade, por se constituir no maior contingente dos atendimentos

Observa-se, assim, que, nas práticas do PAV do NAFAVD, existem poucos elementos de uma perspectiva interseccional, que considera, na articulação com o gênero, outras formas e graus de dispositivos opressivos $^{97}$. Esse achado converge com o que foi encontrado em recente pesquisa que teve por objetivo compreender a experiência de mulheres, cujos companheiros, autores de violência, participaram do PAV do NAFAVD ou do Programa de Prevenção e Combate à Violência Doméstica e Intrafamiliar (PPVCDI) da Prefeitura de Blumenau-SC. Neste estudo detectou-se que a abordagem com os autores de violência é ainda insipiente no plano interseccional ${ }^{98}$.

A praxis acaba por operar uma "despolitização do conceito de gênero", por meio do seu uso associado, frequentemente, ao lugar de atribuições masculinas e femininas, numa ênfase da perspectiva de papéis sociais, como se o relacional do gênero se referisse a homens e mulheres de forma complementar e não ao masculino e ao feminino numa relação poder ${ }^{100}$. O PAV parece movimentar-se numa matriz "cis-heteroconforme e colonial", produzindo silenciamentos sobre as relações de gênero cruzadas com as questões de raça e de corpos dissidentes, cujas gramáticas de gênero e sexualidade se distanciam da heterossexualidade compulsória ${ }^{101}$.

Aspectos de um feminismo liberal, no qual a desigualdade de gênero centra-se com mais força nas relações familiares e com menos intensidade nas relações de gênero entabuladas em todas instâncias da organização social, em especial do Estado 102103104 105, são encontrados na entrevista da/o informante 6, ficando explícita a interpretação da violência: "a briga é relacional. Então, se uma das partes, por exemplo, não vai para o embate, a chance de não ter a grande briga diminui. Nem sempre, mas diminui."

A mitigação do viés interseccional e das discussões da comunicação não violenta para além da família no âmbito do PAV do NAFAVD se conecta com a corrente teórica que Santos e Izumino ${ }^{106}$ chamam de relacional, na qual há relativização da dominação masculina e da vitimação feminina. É possível notar a oblitera-

\footnotetext{
97 DIAS, I. Sociologia da família e do género. 1. ed. Lisboa: Pactor, 2015.

98 NOTHAFT, R.J. Experiências de mulheres no enfrentamento da violência doméstica e familiar e suas relações com os serviços para autores de violência. Tese (Doutorado ao Programa de Pós-Graduação Interdisciplinar em Ciências Humanas). Universidade Federal de Santa Cantarina. Florianopólis, 2020.

99 BEIRAS, A.; CANTERA, L. M. Feminismo pós-estruturalista e masculinidades: contribuições para a intervenção com homens autores de violência contra a mulher. In: BLAY, E. A. (coord.). Feminismos e masculinidades: novos caminhos para enfrentar a violência contra a mulher. São Paulo: Cultura Acadêmica, 2014. p. 31.

100 ARILHA, M. Nações Unidas, população e gênero: homens em perspectiva. Jundiaí: In House, 2010. p. 50.

101 GOMES, C. M. Gênero como categoria de análise decolonial. Civitas, v. 18, n. 1, p. 344, 2018. Disponível em: http://dx.doi. org/10.15448/1984-7289.2018.1.28209. Acesso em: 28 maio 2020.

102 AMÂNCIO, L. O género no discurso das ciências sociais. Análise Social, Lisboa, v. XXXVIII, n. 168, pp. 687-714, out. 2003.

103 PISCITELLI, A. Gênero: a história de um conceito. In: ALMEIDA, H. B.; SZWAKO, J. Diferenças, igualdades. São Paulo: Berlendis \& Vertecchia, 2009. pp. 116-149.

104 CONNELL, R.; PEARSE, R. Gênero, uma perspectiva global. Compreendendo o gênero - da esfera pessoal à política - no mundo contemporâneo. 3. ed. São Paulo: nVersos, 2015.

105 DIAS, I. Sociologia da família e do género. 1. ed. Lisboa: Pactor, 2015.

106 SANTOS, C. M.; IZUMINO, W. P. Violência contra as mulheres e violência de gênero: notas sobre estudos feministas no Brasil. Estudios Interdisciplinares de América Latina y El Caribe da Universidade de Tel Aviv, Tel Aviv, v. 16, n. 1, jan. 2005.
} 
ção da discussão de gênero na sua dimensão organizacional ${ }^{107}$, que demanda a compreensão do sujeito que pratica a violência no âmbito das relações domésticas e familiares, e também como sujeito social e político.

As análises efetuadas até aqui acrescentam e reforçam a literatura brasileira, que tem marcado a necessidade de os PAV serem estruturados num quadro multidisciplinar e psicossocial ${ }^{108}{ }^{109}$, evitando-se que a violência seja discutida somente no campo subjetivo, ou seja, a partir de um ato concreto praticado por um sujeito contra outro, favorecendo o risco de patologização do sujeito e uma interpretação pretensamente neutra do comportamento (como se equivalente à violência pontual, entre estranhos, num contexto distinto daquele das relações de intimidade e sem distinção por ser a vítima do gênero feminino).

Os dados, ainda, sugerem, a partir da presença recorrente nas entrevistas de expressões como "grupo reflexivo", "reflexão", "psicossocial", "educação" e "psicoeducativo", que os profissionais do PAV do NAFAVD interpretam o programa como psicoeducativo, numa orientação reflexiva/responsabilizante ${ }^{110}$.

No caso da metodologia psicoeducativa, as capacitações realizadas com Organizações Não Governamentais $(\mathrm{ONG})$ que trabalham com homens autores de violência parecem ter sido fundamentais nessa construção. De fato, se olharmos para as metodologias das ONG mencionadas pelos/as entrevistados 1 e 8 - Noos $^{111}$ e Albam ${ }^{112}$ —, nota-se que seguem o modelo psicoeducativo ${ }^{113}$ (Acosta, Filho \& Bronz, 2004). Contudo, as práticas profissionais descritas sugerem distanciamento desse modelo. As/os 7 informantes, provavelmente, são instruídos/as (e influenciados/as) pela sua formação de base (6 psicólogas/os e 1 pedagoga/o) e/ou pela equipe (6 têm como parceira/o psicólogas/os e o/a informante 8 trabalha com profissional da área de serviço social).

Em suma, recorrendo ao discurso da/o informante 5, "na prática, o NAFAVD não tem contemplado nem o psicossocial nem o multidisciplinar", sendo, na praxis, um programa mais orientado para um formato "psi”, apesar de não poder ser considerado terapia, devido ao formato grupal e de curta duração, como adverte a/o informante 7 ao alertar que "não é uma psicoterapia, (...) é um atendimento breve e tem um olhar pra questões de psicologia, sociais, fenômeno social e eu vejo até mais."

Esses discursos conduzem à existência, em relação à equipe do NAFAVD, de uma identificação inconsistente da metodologia, o que abre espaço para que as práticas profissionais recorram à origem do serviço e/ ou às bases teóricas da formação inicial dos/das profissionais. A hipótese que ganha contornos é a de que, nas práticas profissionais do PAV do NAFAVAD, prevalece o peso de uma representação social hegemônica, em razão do apelo que faz à memória do grupo ${ }^{114}$.

107 CONNELL, R.; PEARSE, R. Gênero, uma perspectiva global. Compreendendo o gênero — da esfera pessoal à política — no mundo contemporâneo. 3. ed. São Paulo: nVersos, 2015.

108 GONÇALVES, J. P. As contribuições da noção de interseccionalidade e dos estudos feministas pós-coloniais para o campo das intervenções com homens autores de violência doméstica contra as mulheres. In: BEIRAS, A.; Nascimento, M. Homens e violência contra mulheres. Pesquisas e intervenções no contexto brasileiro. Rio de Janeiro: Instituto Noos, 2017. pp. 19-51.

109 BEIRAS, A.; NASCIMENTO, M.; INCROCCI, C. Grupos reflexivos: notas sobre os desafios para a construção de responsabilização, redução de violência e efetividade de programas para homens autores de violência contra as mulheres. In: PASINATO, W. B.; MACHADO, A.; ÁVILA, T. P. (coord.). Politicas públicas de prevenção à violência contra a mulher. Brasília; São Paulo: Fundação Escola; Marcial Pons Brasil. 2019. pp. 275-298.

110 VELOSO, F. G.; NATIVIDADE, C. Metodologias de abordagem dos homens autores de violência contra as mulheres. In: LOPES, P. V.; LEITE, F. Atendimento a homens autores de violência doméstica: desafios à política pública. Rio de Janeiro: Instituto de Estudos da Religião, 2013. pp. 45-64.

111 O Noos é uma ONG que tem, entre as suas atividades, o desenvolvimento de cursos de facilitação de grupos reflexivos de gênero, conforme informações extraídas de: INSTITUTO NOOS. Instituto. Disponível em: http://noos.org.br/instituto/. Acesso em: 22 maio 2020.

112 O Albam é uma ONG que desenvolve grupos reflexivos com homens, conforme informações extraídas de: INSTITUTO ALBAM. Quem somos? Disponível em: http://albam.org.br/quem-somos/ . Acesso em: 28 maio 2020.

113 ACOSTA, F.; BRONZ, A. Desafios para o trabalho com homens em situação de violência com suas parceiras íntimas. In: BLAY, E. A. (coord.). Feminismos e masculinidades: novos caminhos para enfrentar a violência contra a mulher. São Paulo: Cultura Acadêmica, 2014. pp. 139-148.

114 MOSCOVICI, S. Representações sociais: investigações em psicologia social. 11. ed. Petrópolis: Vozes, 2015. 
A atualização da origem "psi” do NAFAVD é também reforçada por memórias arraigadas na justiça. De acordo com o/a informante 5, "ao menos do ponto de vista da linguagem" o sistema de justiça os enxerga como "atendimento psicológico". O/A informante 7 ilustra essa memória ao mencionar que já foi chamado/a para prestar "socorro" a casos de "esquizofrênia e"suicídio".

A força dessa representação social é expressiva, fazendo com que o PAV do NAFAVD, quando convocado a responder a racionalidade do sistema de justiça, não hesite em reafirmar que se trata de um serviço "psi”. Por exemplo, a/o informante 7, ao ser questionada/o sobre o encaminhamento dado ao autor em risco de suicídio, assumiu que o atendeu no formato individual e durante o período de dois a três meses. O peso que a justiça parece exercer nas práticas profissionais dos/das servidores/as, empurrando-as para se adequarem à representação originária do PAV do NAFAVD, pode ser identificada, também, no discurso $\mathrm{da} / \mathrm{o}$ informante 1 , que trouxe relato de atendimento individual dado a autor em quadro de "adoecimento paranoico" por quatro meses.

A análise até aqui efetuada permite sustentar que o modelo teórico do PAV do NAFAVD, assentado numa perspectiva teórica de gênero, que privilegia a metodologia psicoeducativa por meio de equipes multidisciplinares, é obliterado por uma representação hegemônica antiga e também tradicional, disseminada em instituições como a justiça, a produzir uma prática profissional pouco uniforme. A questão que mais interessa aos estudos de gênero é: de onde viria a força motriz dessa representação hegemônica? A hipótese orientadora e motivadora deste estudo é de que estaria na ordem de gênero, fomentadora que é das práticas sociais, por meio dos regimes de gênero ${ }^{115}$.

A ordem de gênero impõe verdades por meio de normas sociais ou de pressão de autoridades (dimensão estrutural) que são dinamizadas pelos regimes de gênero no plano da construção social (dimensão relacional $)^{116}$. Na dimensão estrutural, temos as relações de poder incrustadas cultural e historicamente nas relações de gênero, pois a lei do status desigual dos gêneros não desapareceu e busca, a todo tempo, esgarçar o contrato de igualdade trazido pela modernidade ${ }^{117}$.

A ordem de gênero desigual atua nas instituições justiça e poder executivo, ofuscando as novas representações sociais da equipe e conduzindo suas práticas a um modelo antigo, com menos enfâse ao paradigma da violência como violação de direitos humanos e problema social e público ${ }^{118}$.

Apresentamos doravante outro resultado que ilustra a imponência da ordem de gênero. Trata-se do que a equipe denomina de um programa sem "coluna vertebral"119 (informantes 1, 4, 5, 6, 7 e 8), a fragilizar o seu potencial preventivo. Como alerta a informante 4, "falta definir exatamente o que é o NAFAVD", estabelecer "qual arcabouço teórico exatamente a gente tem", porque, embora exista "um alinhamento, uma base", há a necessidade de "caracterizar melhor e talvez deixar mais claro pra todos" qual é a "nossa linha condutora". O/A informante 8 associa essa evidência ao fato de, no Brasil, a política para autores de violência doméstica contra as mulheres ser incipiente: "eu acho que assim, é um serviço, esse atendimento de homens que não é muito padronizado no Brasil, né, então, já temos essa carência de diretrizes”.

\footnotetext{
115 CONNELL, R.; PEARSE, R. Gênero, uma perspectiva global. Compreendendo o gênero - da esfera pessoal à política - no mundo contemporâneo. 3. ed. São Paulo: nVersos, 2015.

116 CASACA, S. F. Revisitando as teorias sobre a divisão sexual do trabalho. Working Paper SOCIUS, Lisboa, n. 4, 2009. Disponível em: https://www.repository.utl.pt/bitstream/10400.5/1116/1/WP_4_2009.ultima.versao.pdf. Acesso em: 28 maio 2020

117 CASACA, S. F. Revisitando as teorias sobre a divisão sexual do trabalho. Working Paper SOCIUS, Lisboa, n. 4, 2009. Disponível em: https://www.repository.utl.pt/bitstream/10400.5/1116/1/WP_4_2009.ultima.versao.pdf. Acesso em: 28 maio 2020

118 COSTA, D. A intervenção em parceria na violência conjugal contra as mulheres: um modelo inovador? 2011. 395 f. Tese (Doutorado em Sociologia) - Universidade Aberta, Lisboa, 2011. Disponível em: https://repositorioaberto.uab.pt/handle/10400.2/1813. Acesso em: 28 maio 2020.

119 A expressão "coluna vertebral" é emprestada do discurso da/o informante 1 para se referir à ausência de estrutura única do serviço prestado, cujos reflexos seriam práticas não uniformizadas.
} 
Como alertam Beiras, Nascimento e Incrocci ${ }^{120}$, a "falta de uma política nacional específica para HAV impede a consolidação de ações nesse campo, constituindo-se em um problema desde a criação da Lei Maria da Penha e que persiste até a atualidade". Lembramos que, no contexto brasileiro, cresce o fomento à políticas de encarceramento, com fortes entraves ao desenvolvimento de ações na seara das alternativas penais, a minar a força dos PAV como estratégia de prevenção à violência de gênero e de promoção de justiça social ${ }^{121}$.

É possível ainda deduzir que o PAV do NAFAVD sofre de contínua desinstitucionalização, o que o torna aberto a ingerências com potencial para descaracterizá-lo, tornando-se permeável à ordem de gênero. Analisando as raízes dessa evidência, a/o informante 5 declara que o NAFAVD é um órgão que aborda um tema que "está em foco", porém encontra-se vinculado a uma secretaria "sem força” (política e de definição programática). A (aparente) falta de investimento político concretiza-se, dentre outros aspetos, no que a/o informante 6 apresenta acerca de determinada unidade ter ficado sem telefone para convocar os autores. Além disso, institucionalmente, os NAFAVD não têm sede própria e ocupam espaços cedidos pelo sistema de justiça.

Essa desimportância da temática de gênero, no âmbito do poder executivo local, pode ser interpretada como barreira à implementação da igualdade de gênero e prevenção da violência de gênero. Nas relações entre o poder executivo e os/as profissionais que aplicam o PAV do NAFAVD, ganha proeminência o discurso de regulação (controle da ordem social) ${ }^{122}$, que busca energizar a cultura androcêntrica. Essa hipótese merece estudo autônomo, mas resulta desta pesquisa com muita consistência.

A questão que procuramos responder no item seguinte interroga: de que modo atua a ordem de gênero? Sendo o PAV do NAFAV permeável, conforme se demonstrou, qual é o processo de influência efetiva, concreta, sobre as práticas? Como a ordem de gênero penetra nas ações?

\subsection{Ultrapassando obstáculos: ações transformadoras}

O PAV do NAFAVD foi criado com base em modelo sensível ao discurso de gênero. Contudo, na passagem para o contexto, ou seja, quando é aplicado pelos/as profissionais, esse modelo fica sujeito a uma lógica relacional, entre estrutura social e ação individual, que se moldam ${ }^{123}$, e na qual ganha espaço a ação social transformativa, influenciada pela subjetividade dos sujeitos e também pelos campos ${ }^{124}$.

Observamos agência dos profissionais, com potencial transformador em duas ações em específico: as reuniões semanais da equipe chamados pelos/as informantes de "sextas de equipe" e as capacitações individuais e coletivas, que proporcionam análise reflexiva e conhecimento.

Nas "sextas de equipe", os profissionais do NAFAVD discutem, conforme nos explica a/o entrevistada/o 1, questões "técnicas com vivências", gerando um lugar de "capacitação continuada". Para a/o entrevistada/o 4, nas reuniões de equipe, profissionais com mestrado e doutorado na área de gênero trazem ideias e discussões "do ponto de vista do gênero", o que "afina um pouco melhor na medida do possível a nossa atuação". As "sextas de equipe", inclusive, impulsionaram a elaboração do manual de atuação do PAV do NAFAVD, para indicar práticas profissionais imbrincadas com uma atuação pautada pela responsabilidade social ${ }^{125}$.

\footnotetext{
120 BEIRAS, A.; NASCIMENTO, M.; INCROCCI, C. Grupos reflexivos: notas sobre os desafios para a construção de responsabilização, redução de violência e efetividade de programas para homens autores de violência contra as mulheres. In: PASINATO, W. B.; MACHADO, A.; ÁVILA, T. P. (coord.). Políticas públicas de prevenção à violência contra a mulber. Brasília; São Paulo: Fundação Escola; Marcial Pons Brasil. 2019. p. 291.

121 COLLINS, P.H; BILGE, S. Interseccionalidad. Madrid: Ediciones Morata, 2019.

122 NOGUEIRA, C. A análise do discurso. In: ALMEIDA, L.; FERNANDES, E. Métodos e técnicas de avaliação: novos contributos para a prática e investigação. Braga: CEEP, 2001.

123 GRENFELL, M. Pierre Bourdieu: conceitos fundamentais. Petropólis: Vozes, 2018.

124 BOURDIEU, P. Razões práticas sobre a teoria da ação. 7. ed. São Paulo: Papirus, 2005.

125 PINTO, C. Representações e práticas do empowerment nos trabalhadores sociais. 2011. 522 f. Tese (Doutorado em Ciências Sociais) - Instituto Superior de Ciências Sociais e Políticas, Universidade Técnica de Lisboa, Lisboa, 2011.
} 
As capacitações individuais, por sua vez, consistem na busca autônoma de formação na área dos estudos de gênero. Dos/as 9 informantes, 3 possuem mestrado e/ou doutorado na área de estudos de gênero. Um/ uma menciona que seus "estudos em gênero contribuíram para articular o programa e ajudar a equipe" e "a estruturá-lo melhor". Nas entrevistas desses/as informantes, está (mais) presente uma perspetiva de gênero mais crítica, o que contribui para fortalecer a hipótese de que os estudos de gênero transformam práticas profissionais por via de uma análise crítica dos fins, objetivos e modos de implementação de programas como o PAV.

Quantos aos outros 6 informantes, 1 tem mestrado; 4, especializações e 1 é graduado/a. No entanto, essas formações não são na área de estudos de gênero. A imersão desses profissionais nessa temática se deu por meio de capacitações coletivas promovidas pela própria equipe ou por iniciativa pessoal.

A/O informante 7 informa que a primeira capacitação do PAV do NAFAVD foi paga pela própria equipe e que, hoje, ela segue "buscando também por conta (...) lendo e procurando cursos" a distância. A/O informante 8 declara que, depois de uma capacitação promovida em 2013 pelo poder executivo local, foi se capacitando por conta própria, "indo atrás mesmo", destacando que, com outros/as integrantes da equipe, fizeram um curso com a ONG ALBAM ${ }^{126}$, definido por ele/a como marcante, porquanto tenha produzido aprofundamento nas questões da dimensão do poder nas relações de gênero.

Esses resultados encontram ressonância na pesquisa de Linhares e Pitanguy, onde foi documentado que os PAV, em 9 capitais brasileiras, não contam com ações institucionais e regulares de capacitação, mas com o "empenho pessoal" ${ }^{127} \mathrm{dos} /$ as profissionais envolvidos/as.

O prejuízo é que a política pública voltada para autores de violência contra mulheres se estruture numa lógica de despolitização, com uso do conceito de gênero sem que seja levado em conta o seu espectro simbólico, no qual estão a construção das masculinidades e a sua relação na composição do gênero de maneiras distintas ${ }^{128}$. Consoante Arilha ${ }^{129}$, um dos caminhos possíveis para buscar transformações nas relações de gênero é um processo que vá além da discussão dos papéis sexuais e que integre o "corpo no âmbito reprodutivo, considerando que os corpos reprodutivos são objetos e agentes que constroem práticas institucionais".

Outro impacto negativo derivado da ausência de capacitação consiste na assunção da interseccionalidade dentro de um compromisso meramente formal, deixando de "incorporar um ethos de justiça social" 130 e reatualizando, por meio da colonialidade, as hierarquias de poder entre negros/as e brancos/as, entre mulheres brancas e negras e entre classes. Sem esse olhar, questões outras de classe e de raça que também moldam a ordem de gênero e também criam sentidos de masculinidade/feminilidade — em grande medida permeados por sentidos hegemônicos da branquitude — ficam alheias às intervenções. Desta forma, o PAV do NAFAVD não somente se torna permeável a uma ordem de gênero, mas também a uma ordem racializada, a uma ordem colonial de gênero.

Os discursos permitem, ainda, perceber que as práticas "transgressoras" dos/das profissionais do NAFAVD conseguem se manter por meio de um "discurso técnico", que visa à "sensibilização" das instituições totais. Alguns/mas profissionais, na relação com as instituições sistema de justiça e executivo, conseguem estabelecer campo de força a partir do "discurso técnico", dando, assim, uma indicação de que, no campo da

\footnotetext{
126 O Albam é uma ONG que desenvolve grupos reflexivos com homens, conforme informações extraídas de: INSTITUTO ALBAM. Quem somos? Disponível em: http://albam.org.br/quem-somos/ . Acesso em: 28 maio 2020.

127 LINHARES, L. B.; PITANGUY, J. Violência contra as mulheres: os serviços de responsabilização dos homens autores de vioLência. Rio de Janeiro: CEPIA, 2016. p. 61.

128 CONNELL, R.; PEARSE, R. Gênero, uma perspectiva global. Compreendendo o gênero - da esfera pessoal à política - no mundo contemporâneo. 3. ed. São Paulo: nVersos, 2015.

129 ARILHA, M. Nações Unidas, população e gênero: homens em perspectiva. Jundiaí: In House, 2010. p. 56.

130 COLLINS, P. H. Se perdeu na tradução? Feminismo negro, interseccionalidade e política emancipatória. Revista Parágrafo, v. 5, n. 1, pp. 6-17, jan./jun. 2017.
} 
ação, há poder para a construção de uma realidade social ${ }^{131}$. No entanto, nem sempre esse discurso técnico é acatado. É o que se dá com a questão do tempo. Parece haver um tempo do PAV do NAFAVD e um tempo da justiça, não coincidentes. $\mathrm{O} / \mathrm{A}$ informante 8 menciona a existência desses dois tempos e propõe que estes sejam coordenados de forma mais eficiente, como maneira de compor uma comunicação que seria "falha". $\mathrm{O} / \mathrm{A}$ informante 2 pondera que "justiça fica presa num tempo", e traz como exemplo a questão da execução penal, cujo tempo de cumprimento de pena é muito menor do que o do acompanhamento proposto pelo PAV do NAFAVD. O/A informante 1 ainda alerta que o vínculo com o sistema de justiça não necessariamente resulta em diálogo, conduzindo-se à interelação por uma lógica impositiva.

Essas falas indicam práticas de fragilização do modelo coordenado em razão do peso oriundo da instituição justiça, cujo capital simbólico favorece os discursos totalizadores ${ }^{132}$. A solução para a compatibilização dos tempos do PAV do NAFAVD e do sistema de justiça seria uma gestão técnica e forte, que, conforme restou assente ao longo das entrevistas, não tem sido priorizada nos últimos governos do DF.

Mais uma vez vem à tona a força das estruturas sobre o PAV do NAFAVD, impelindo-o a se distanciar de um modelo teórico voltado para a igualdade de gênero. Contudo, como bem lembra Bourdieu ${ }^{133}$, na estrutura há, também, dualidade e, por essa razão, o PAV do NAFAVD “ainda consegue mesmo na UTI fazer um trabalho diferente" (informante 5).

\section{Considerações finais}

Movidoas/os pela ideia de que os PAV pudessem ser "microcosmos do social"134, constituindo-se em espaços de alargamento das fronteiras entre feminino e masculino ou mesmo de interface e re(construção) da ordem de gênero desigual e atravessada por marcadores interseccionais, buscamos imergir na realidade de um PAV específico, o PAV do NAFAVD.

Deparamo-nos com um objeto em ação há mais de dezesseis anos, mas com poucas fontes que pudessem delineá-lo. Havia, no início da pesquisa (realidade que permanece), tão somente informações sobre os seus objetivos no sítio eletrônico da então Secretaria de Estado do Trabalho, Desenvolvimento Social, Mulheres, Igualdade Racial e Direitos Humanos da Mulher do DF. Buscamos, na moldura do quadro teórico dos estudos de gênero e interseccionais, problematizar esse objeto e compreendê-lo com base nos sujeitos que o constroem, por via das suas representações sociais e das suas práticas profissionais.

Nossa hipótese orientadora, lastreada na literatura dos estudos de gênero e interseccionais, na LMP e inspirada pelo conhecimento empírico, sugeria que o PAV do NAFAVD foi criado para fins de prevenção da violência de gênero, tendo-lhe sido definidos objetivos de contenção e redução dessa violência, que não são manifestados nas representações sociais e práticas profissionais, ficando permeável à influência de uma ordem de gênero, que se consolida e reproduz.

Essa hipótese orientadora da pesquisa empírica fica confirmada em parte. Concluimos que o PAV do NAFAVD possui modelo teórico baseado em perspetiva sensível ao discurso de gênero, se orienta para uma metodologia psicoeducativa e tem objetivos amplos (pouco diretivos). No entanto, na passagem para o contexto, o discurso oral captado pelos/as profissinais que o interpretam e o praticam revelou um programa permeável à ordem de gênero, colocando em perigo os fins e os objetivos que visa alcançar, descaracterizando-se, portanto.

131 BOURDIEU, P. Razões práticas sobre a teoria da ação. 7. ed. São Paulo: Papirus, 2005.

132 NOGUEIRA, C. A análise do discurso. In: ALMEIDA, L.; FERNANDES, E. Métodos e técnicas de avaliação: novos contributos para a prática e investigação. Braga: CEEP, 2001.

133 BOURDIEU, P. Råões práticas sobre a teoria da ação. 7. ed. São Paulo: Papirus, 2005.

134 SAYÃO, D. T. Corpo, poder e dominação: um diálogo com Michelle Perrot e Pierre Bourdieu. Perspectiva, Florianópolis, v. 21, n. 1, p. 124, jan./jun. 2003. Disponível em: https://periodicos.ufsc.br/index.php/perspectiva/article/viewFile/10210/9437. Acesso em: 28 maio 2020. 
Por exemplo, quanto ao aporte teórico, ante a ausência de capacitações institucionais e continuadas, as relações de gênero tendem a ser entendidas parcelarmente, no quadrante dos papéis sociais, sem cruzamentos com outras gramáticas relacionais que interagem no contexto das relações de poder, como raça, classe, geração e sexualidade, empobrecendo, dessa forma, a dimensão estrutural das relações de gênero ${ }^{135} 136$ e a noção de interseccionalidade como ferramenta de justiça social ${ }^{137}$. Nesse particular, para Collins \& Bilge ${ }^{138}$, políticas construídas à margem do conceito de intersseccionalidade, ou seja, desenhadas de forma monotemática para populações que vivenciam opressões distintas, diminuem seu potencial de efetividade, podendo, muitas vezes, assumir aspectos danosos.

Relativamente à metodologia, o caráter multidisciplinar do programa é desvirtuado pela presença preponderante de profissionais da psicologia (dos 9 informantes, 7 são psicólogos). Ainda que esses/as profissionais tenham noção da dimensão estrutural da VD contra a mulher, a sua formação de base nem sempre permite abarcar a complexidade dessa espécie de violência como fenômeno com quatro dimensões do gênero: estrutural, relacional, emocional e simbólica ${ }^{139}$. Amado ${ }^{140}$ realça que programas que assentam a causa da violência numa questão patológica estruturam sua equipe com profissionais da saúde mental, mas, se a violência é compreendida a partir de causas complexas, o corpo técnico será interdisciplinar.

Os objetivos definidos para o programa, seja no pensamento (representação social), seja no campo da ação, apontam para um discurso imerso em diretivas pouco uniformes, influenciadas por uma política pública nacional e local de baixa institucionalidade ${ }^{141}{ }^{142}$, a revelar o poder de uma ordem de gênero que oblitera temas relacionados às relações de poder e intersecções delas decorrentes ${ }^{143}$.

Contudo concluímos, também, que há um discurso de resistência, que busca friccionar os "discursos totalizadores" 144 _ os/as profissionais com formação na área dos estudos de gênero produzem saberes para que o PAV, de fato, seja uma ferramenta que respeita o seu modelo teórico. Esse modelo pode se constituir em baliza para construção de instrumentos de monitoramento e avaliação, etapas fundamentais para o desenho de uma eficienete política pública ${ }^{145}$.

\footnotetext{
135 CONNELL, R.; PEARSE, R. Gênero, uma perspectiva global. Compreendendo o gênero - da esfera pessoal à política - no mundo contemporâneo. 3. ed. São Paulo: nVersos, 2015.

136 GOMES, C. M. Gênero como categoria de análise decolonial. Civitas, v. 18, n. 1, pp. 65-82, 2018. Disponível em: http://dx.doi. org/10.15448/1984-7289.2018.1.28209. Acesso em: 28 maio 2020.

137 COLLINS, P. H. Se perdeu na tradução? Feminismo negro, interseccionalidade e política emancipatória. Revista Parágrafo, v. 5 , n. 1, pp. 6-17, jan./jun. 2017.

138 COLLINS, P.H; BILGE, S. Interseccionalidad. Madrid: Ediciones Morata, 2019.

139 CONNELL, R.; PEARSE, R. Gênero, uma perspectiva global. Compreendendo o gênero - da esfera pessoal à política - no mundo contemporâneo. 3. ed. São Paulo: nVersos, 2015.

140 AMADO, R. M. Os serviços de educação e responsabilização para homens e autores de violência contra as mulheres: uma análise de quadros interpretativos, modelos de intervenção e atores. 2014. 87 f. Dissertação (Mestrado em Sociologia) - Faculdade de Economia, Universidade de Coimbra, Coimbra, 2014. Disponível em: https://core.ac.uk/download/pdf/43576976.pdf. Acesso em: 28 maio 2020. 141 AMADO, R. M. Os serviços de educação e responsabilização para homens e autores de violência contra as mulheres: uma análise de quadros interpretativos, modelos de intervenção e atores. 2014. 87 f. Dissertação (Mestrado em Sociologia) - Faculdade de Economia, Universidade de Coimbra, Coimbra, 2014. Disponível em: https://core.ac.uk/download/pdf/43576976.pdf. Acesso em: 28 maio 2020. 142 BEIRAS, A.; NASCIMENTO, M.; INCROCCI, C. Grupos reflexivos: notas sobre os desafios para a construção de responsabilização, redução de violência e efetividade de programas para homens autores de violência contra as mulheres. In: PASINATO, W. B.; MACHADO, A.; ÁVILA, T. P. (coord.). Políticas públicas de prevenção à violência contra a mulher. Brasília; São Paulo: Fundação Escola; Marcial Pons Brasil. 2019. pp. 275-298.

143 MATTOS, P. As abordagens da "sociologia disposicional" e da "interseccionalidade": articulando uma proposta para os estudos de gênero. In: BODEMER, K. Cultura, sociedad y democracia en América Latina. Espanha: Iberoamericana Editorial Vervuert, 2012. pp. 251-270.

144 NOGUEIRA, C. A análise do discurso. In: ALMEIDA, L.; FERNANDES, E. Métodos e técnicas de avaliação: novos contributos para a prática e investigação. Braga: CEEP, 2001. p. 13.

145 BEIRAS, A.; NASCIMENTO, M.; INCROCCI, C. Grupos reflexivos: notas sobre os desafios para a construção de responsabilização, redução de violência e efetividade de programas para homens autores de violência contra as mulheres. In: PASINATO, W. B.; MACHADO, A.; ÁVILA, T. P. (coord.). Políticas públicas de prevenção à violência contra a mulber. Brasília; São Paulo: Fundação Escola; Marcial Pons Brasil. 2019. pp. 275-298.
} 
Esse longo caminho, que ainda precisa ser percorrido, não apaga, no entanto, o PAV do NAFAVD como espaço institucional com força e potência para provocar ou ao menos iniciar inversão na lógica masculina, normalmente dissociada de ritos de compartilhamento de sentimentos ${ }^{146}$ e marcada e reforçada por uma generalização do privado como lugar intocável e difícil de alcançar pelo direito; e como programa que, integrado numa política pública sólida e coerente, poderia cumprir o fim maior de prevenir a violência de gênero contra as mulheres, nas relações de intimidade.

\section{Referências}

ACOSTA, F.; BRONZ, A. Desafios para o trabalho com homens em situação de violência com suas parceiras íntimas. In: BLAY, E. A. (coord.). Feminismos e masculinidades: novos caminhos para enfrentar a violência contra a mulher. São Paulo: Cultura Acadêmica, 2014. pp. 139-148.

AGUIAR, L. H. Gênero e masculinidades: follow-up de uma intervenção com homens autores de violência conjugal. 2009. 175 f. Dissertação (Mestrado em Psicologia) - Instituto de Psicologia, Universidade de Brasília, Brasília, 2009. Disponível em: http://repositorio.unb.br/bitstream/10482/8188/1/2009_LuizHenriqueMachadoAguiar.pdf. Acesso em: 28 maio 2020.

ALMEIDA, S. S. Essa violência mal-dita. In: ALMEIDA, S. S. Violência de gênero e políticas públicas. Rio de Janeiro: UFRJ, 2007. pp. 23-41.

AMADO, R. M. Os serviços de educação e responsabilização para homens e autores de violência contra as mulheres: uma análise de quadros interpretativos, modelos de intervenção e atores. 2014. 87 f. Dissertação (Mestrado em Sociologia) - Faculdade de Economia, Universidade de Coimbra, Coimbra, 2014. Disponível em: https:// core.ac.uk/download/pdf/43576976.pdf. Acesso em: 28 maio 2020.

AMÂNCIO, L. O género no discurso das ciências sociais. Análise Social, Lisboa, v. XXXVIII, n. 168, pp. 687-714, out. 2003.

ANTEZANA, A. P. Intervenção com homens que praticam violência contra seus cônjuges: reformulações teórico-conceituais para uma proposta de intervenção construtivista-narrativista com perspectiva de gênero. Nova Perspectiva Sistêmica, Rio de Janeiro, v. 21, n. 42, pp. 9-27, abr. 2012. Disponível em: https://www.revistanps.com.br/nps/article/view/121/96. Acesso em: 28 maio 2020.

ARILHA, M. Nações Unidas, população e gênero: homens em perspectiva. Jundiaí: In House, 2010.

BADINTER, E. XY: sobre a identidade masculina. 2. ed. Rio de Janeiro: Nova Fronteira, 1992.

BANDEIRA, L. M. Violência de gênero: a construção de um campo teórico e de investigação. Revista Sociedade e Estado, Brasília, v. 29, n. 2, pp. 449-469, maio/ago. 2014.

BEIRAS, A. Relatório mapeamento de serviços de atenção grupal a homens autores de violência doméstica contra mulheres no contexto brasileiro. Rio de Janeiro: Instituto Noos, 2014. Disponível em: http://www.noos.org.br/portal/ wp-content/uploads/2015/04/Relatorio-Mapeamento-SHAV_site.pdf. Acesso em: 28 maio 2020.

BEIRAS, A.; BRONZ, A. Metodologia de grupos reflexivos de gênero. Rio de Janeiro: Instituto Noos, 2016. Disponível em: http://noos.org.br/wp-content/uploads/2018/08/Metodologia-Noos_PDF-final.pdf. Acesso em: 22 maio 2020.

BEIRAS, A.; CANTERA, L. M. Feminismo pós-estruturalista e masculinidades: contribuições para a intervenção com homens autores de violência contra a mulher. In: BLAY, E. A. (coord.). Feminismos e masculinidades: novos caminhos para enfrentar a violência contra a mulher. São Paulo: Cultura Acadêmica, 2014. pp. 29-44.

${ }_{146}$ BADINTER, E. XY: sobre a identidade masculina. 2. ed. Rio de Janeiro: Nova Fronteira, 1992. 
BEIRAS, A.; NASCIMENTO, M.; INCROCCI, C. Grupos reflexivos: notas sobre os desafios para a construção de responsabilização, redução de violência e efetividade de programas para homens autores de violência contra as mulheres. In: PASINATO, W. B.; MACHADO, A.; ÁVILA, T. P. (coord.). Políticas públicas de prevenção à violência contra a mulher. Brasilia; São Paulo: Fundação Escola; Marcial Pons Brasil. 2019. pp. 275-298.

BELEZA, T. P. Anjos e monstros: a construção das relações de género no Direito Penal. Ex aequo, n. 10, pp. 29-40, 2004.

BOURDIEU, P. Razões práticas sobre a teoria da ação. 7. ed. São Paulo: Papirus, 2005.

BRASIL. Lei no 11.340, de 7 de agosto de 2006. Portal da Legislação, Brasília, 2006. Disponível em: http:// www.planalto.gov.br/ccivil_03/_Ato2004-2006/2006/Lei/L11340.htm. Acesso em: 28 maio 2020.

BRASIL. Mecanismo Nacional de Prevenção e Combate à tortura (MNPCT). Relatório Anual 2017. 2018.

BRASIL. Lei n 13.984 , de 3 de abril de 2020. Portal da Legislação, Brasília, 2020. Disponível em: http:/ /www. in.gov.br/en/web/dou/-/lei-n-13.984-de-3-de-abril-de-2020-251138826. Acesso em: 22 maio 2020.

CASACA, S. F. Revisitando as teorias sobre a divisão sexual do trabalho. Working Paper SOCIUS, Lisboa, n. 4, 2009. Disponível em: https://www.repository.utl.pt/bitstream/10400.5/1116/1/WP_4_2009.ultima. versao.pdf. Acesso em: 28 maio 2020.

CASALEIRO, P. O poder do direito e o poder do feminismo: revisão crítica da proposta teórica de Carol Smart. Ex aequo, n. 29, pp. 39-53, 2014.

CEREJO, D. Intervenção com agressores em Portugal: características e caminhos de intervenção com agressores conjugais. In: NEVES, S.; COSTA, D. Violências de género. Lisboa: ISCSP-CIEG, 2017. pp. 283-315.

COLLINS, P. H. Se perdeu na tradução? Feminismo negro, interseccionalidade e política emancipatória. Revista Parágrafo, v. 5, n. 1, pp. 6-17, jan./jun. 2017.

COLLINS, P.H; BILGE, S. Interseccionalidad. Madrid: Ediciones Morata, 2019.

CONNELL, R. Gênero em termos globais. 1. ed. São Paulo: nVersos, 2016.

CONNELL, R.; PEARSE, R. Gênero, uma perspectiva global. Compreendendo o gênero - da esfera pessoal à política - no mundo contemporâneo. 3. ed. São Paulo: nVersos, 2015.

COSTA, D. A intervenção em parceria na violência conjugal contra as mulheres: um modelo inovador? 2011. $395 \mathrm{f}$. Tese (Doutorado em Sociologia) - Universidade Aberta, Lisboa, 2011. Disponível em: https:/ / repositorioaberto.uab.pt/handle/10400.2/1813. Acesso em: 28 maio 2020.

COSTA, D. A evolução de políticas públicas em Portugal na área da violência doméstica. In: I. D. (coord.). Violência doméstica e de género: uma abordagem multidisciplinar. Lisboa: Pactor, 2018. pp. 123-156.

COSTA, D.; BAPTISTA, I. Relatório de investigação realizada na Equipa Lisboa Penal 5 da Direção Geral de Reinserção e Serviços Prisionais. Lisboa: ISCSP, 2019.

CRENSHAW, K. Demarginalizing the intersection of race and sex: a black feminist critique of antidiscrimination doctrine, feminist theory and antiracist politics. The University of Chicago Legal Forum, v. 1, n. 8, pp. 139-167, 1989. Disponível em: http://chicagounbound.uchicago.edu/uclf/vol1989/iss1/8. Acesso em: 28 maio 2020.

DAY, A.; CHUNG, D.; O’LEARY, P. Programs for men who perpetrate domestic violence: an examination of the issues underlying the effectiveness of intervention programs. Journal of Family Violence, v. 24, n. 3, pp. 203-212, 2009.

DIAS, I. Sociologia da familia e do género. 1. ed. Lisboa: Pactor, 2015. 
DISTRITO FEDERAL. Crimes de violência doméstica, segundo a Lei no 11.340/2006 - "Lei Maria da Penha" - comparativo do $1^{\circ}$ trimestre dos anos de 2019 e 2020, por Região Administrativa e acompanhamento dos últimos anos no Distrito Federal. Brasília: SESP-DF, 2020. Disponível em: http://www.ssp.df.gov.br/ wp-conteudo/uploads/2017/11/An\%C3\%A1lise-FSP-016_2020-Viol\%C3\%AAncia-Dom\%C3\%A9sticano-DF.pdf . Acesso em: 9 mar. 2020.

DISTRITO FEDERAL. Secretaria de Estado da Mulher. Atendimento à Mulher. Núcleos de Atendimento à Família e aos Autores de Violência Doméstica. Disponível em: http://www.mulher.df.gov.br/nafavds/. Acesso em: 21 set. 2019.

DISTRITO FEDERAL. Secretaria de Estado da Mulher. I Plano Distrital de Politicas para as Mulheres 20142015. Brasília, 2014. Disponível em: http://www.mulher.df.gov.br/wp-conteudo/uploads/2017/11/I-Plano-Distrital-de-Políticas-para-as-Mulheres.pdf. Acesso em: 28 maio 2020.

DISTRITO FEDERAL. Secretaria de Estado da Mulher. Sobre a Secretaria. Disponível em: http://www. mulher.df.gov.br/sedestmidh/. Acesso em: 31 maio 2019.

GOMES, C. M. Gênero como categoria de análise decolonial. Civitas, v. 18, n. 1, pp. 65-82, 2018. Disponível em: http:/ /dx.doi.org/10.15448/1984-7289.2018.1.28209. Acesso em: 28 maio 2020.

GONÇALVES, J. P. As contribuições da noção de interseccionalidade e dos estudos feministas pós-coloniais para o campo das intervenções com homens autores de violência doméstica contra as mulheres. In: BEIRAS, A.; Nascimento, M. Homens e violência contra mulheres. Pesquisas e intervenções no contexto brasileiro. Rio de Janeiro: Instituto Noos, 2017. pp. 19-51.

GONDOLF, E. W. The weak evidence for batterer program alternatives. Aggression and Violent Behavior, v. 16, n. 4, pp. 347-353, jul./ago. 2011.

GRENFELL, M. Pierre Bourdieu: conceitos fundamentais. Petropólis: Vozes, 2018.

GUERRA, I. C. Pesquisa qualitativa e análise de conteúdo: sentidos e formas de uso. 1. ed. Estoril: Principia, 2006.

INSTITUTO ALBAM. Quem somos? Disponível em: http://albam.org.br/quem-somos/. Acesso em: 28 maio 2020.

INSTITUTO MARIA DA PENHA. Relógios da Violência. Disponível em: http://www.relogiosdaviolencia. com.br/\#. Acesso em: 13 mar. 2020.

INSTITUTO NOOS. Instituto. Disponível em: http://noos.org.br/instituto/. Acesso em: 22 maio 2020.

JAHNKE, H. R. O conceito de compreensão na sociologia de Max Weber. Coimbra: Imprensa da Universidade de Coimbra, 2011. Disponível em: http://dx.doi.org/10.14195/978-989-260749-8. Acesso em: 28 maio 2020.

JODELET, D. Réflexions sur le traitement de la notion de représentation sociale en psychologie sociale. Comunication. Information Médias Théories, v. 6, n. 2-3, pp. 14-41, 1984. Disponível em: https:/ /www.persee.fr/ doc/comin_1189-3788_1984_num_6_2_1284. Acesso em: 28 maio 2020.

KAUFMANN, J.-C. A entrevista compreensiva - um guia para pesquisa de campo. 3. ed. (T. d. Abreu, \& L. Florencio, Trads.) Petropólis, RJ: Vozes. 2013.

KELLY, L.; WESTMARLAND, N. Domestic violence perpetrator programmes: steps towards change. Project Mirabal Final Report. Londres; Durham: London Metropolitan University and Durham University, 2015.

LATTANZIO, F. F.; BARBOSA, R. R. Grupos de gênero nas intervenções com as violências masculinas: paradoxos de identidade, responsabilização e vias de abertura. In: LOPES, P. V.; LEITE, F. Atendimento a homens autores de violência doméstica: desafios à política pública. 1. ed. Rio de Janeiro: ISER, 2013. pp. 87-105.

LINHARES, L. B.; PITANGUY, J. Violência contra as mulheres: os serviços de responsabilização dos homens autores de vioLência. Rio de Janeiro: CEPIA, 2016. 
MANITA, C. A intervenção em agressores no contexto da violência doméstica em Portugal: estudo preliminar de caracterização. Lisboa: Comissão para Igualdade e para os Direitos da Mulher, 2005.

MARCONI, M., LAKATOS, E. M. Fundamentos da metodologia científica. 5. ed. São Paulo: Atlas, 2003.

MATTOS, P. As abordagens da "sociologia disposicional" e da "interseccionalidade": articulando uma proposta para os estudos de gênero. In: BODEMER, K. Cultura, sociedad y democracia en América Latina. Espanha: Iberoamericana Editorial Vervuert, 2012. pp. 251-270.

MINISTÉRIO PÚBLICO DO DISTRITO FEDERAL E TERRITÓRIOS (MPDFT). Núcleo de Direitos Humanos. Núcleo de Gênero. Resumo executivo. sítio eletrônico, Disponível emacessado em 21 de setembro de 2019: http://www.mpdft.mp.br/portal/pdf/noticias/maio_2019/RESUMO_EXECUTIVO.pdf. Acesso em: 21 set. 2019.

MONTEIRO, A. C. Autores de violência doméstica e familiar: um estudo sobre um grupo de reflexão no Paranoá/DF. 2014. 183 f. Dissertação (Mestrado em Sociologia) - Departamento de Sociologia, Instituto de Ciências Sociais, Universidade de Brasília, Brasília, 2014.

MOSCOVICI, S. Representações sociais: investigações em psicologia social. 11. ed. Petrópolis: Vozes, 2015.

NOGUEIRA, C. A análise do discurso. In: ALMEIDA, L.; FERNANDES, E. Métodos e técnicas de avaliação: novos contributos para a prática e investigação. Braga: CEEP, 2001.

NOTHAFT, R.J. Experiências de mulheres no enfrentamento da violência doméstica e familiar e suas relaçoes com os serviços para autores de violência. Tese (Doutorado ao Programa de Pós-Graduação Interdisciplinar em Ciências Humanas). Universidade Federal de Santa Cantarina. Florianopólis, 2020.

PASINATO, W.; MACHADO, A.; ÁVILA, T. P. Políticas públicas de prevenção à violência doméstica e familiar contra as mulheres. In: Pasinato, W.; Machado, A.; ÁVILA, T. P. Políticas públicas de prevenção à violência contra a mulher: direito, transdisciplinariedade \& pesquisas sociojurídicas. v. 6. Brasília; São Paulo: Fundação Escola; Marcial Pons, 2019.

PINTO, C. Representações e práticas do empowerment nos trabalhadores sociais. 2011. 522 f. Tese (Doutorado em Ciências Sociais) - Instituto Superior de Ciências Sociais e Políticas, Universidade Técnica de Lisboa, Lisboa, 2011.

PISCITELLI, A. Gênero: a história de um conceito. In: ALMEIDA, H. B.; SZWAKO, J. Diferenças, igualdades. São Paulo: Berlendis \& Vertecchia, 2009. pp. 116-149.

PITANGUY, J., \& BASTERD, L. L. Grupos reflexivos: notas sobre os desafios para a construção de responsabilização, redução de violência e efetividade de programas para homens autores de violência contra as mulheres. Em W. Pasinato, B. A. Machado, \& T. P. Ávila (coord.). Políticas públicas de prevenção à violência contra a mulher. Brasília; São Paulo: Fundação Escola; Marcial Pons Brasil. 2019. pp. 253- 274

PORTO, M. S. Crenças, valores e representações sociais da violência. Sociologias, Porto Alegre, a. 8, n. 16, pp. 250-273, jul./dez. 2006.

QUIVY, R.; CAMPENHOUDT, L. Manual de investigação em ciências sociais. 7. ed. Lisboa: Gradiva, 2017.

SANTOS, C. M.; IZUMINO, W. P. Violência contra as mulheres e violência de gênero: notas sobre estudos feministas no Brasil. Estudios Interdisciplinares de América Latina y El Caribe da Universidade de Tel Aviv, Tel Aviv, v. 16, n. 1, jan. 2005.

SAYÃO, D. T. Corpo, poder e dominação: um diálogo com Michelle Perrot e Pierre Bourdieu. Perspectiva, Florianópolis, v. 21, n. 1, pp. 121-149, jan./jun. 2003. Disponível em: https:/ / periodicos.ufsc.br/index.php/ perspectiva/article/viewFile/10210/9437. Acesso em: 28 maio 2020.

SCOTT, J. Gênero: uma categoria útil de análise histórica. In: Holanda, H. B. Pensamento feminista: conceitos 
fundamentais. Rio de Janeiro: Bazar do tempo, 2019. pp. 49-80.

SEGATO, R. L. Las estructuras elementares de la violencia: ensayos sobre género entre la antropologia, el psicoanálisis y los derechos humanos. Bernal: Universidad Nacional de Quilmes, 2003.

SILVA, A. C. Violência por parceiro intimo: o acompanhamento ao homem autor da violência. 2016. $260 \mathrm{f}$. Tese (Doutorado em Saúde Coletiva) - Centro de Ciências da Saúde, Programa de Pós-graduação em Saúde Coletiva, Universidade Federal de Santa Catarina, Florianópolis, 2016.

STOCK, B. S. Violencia contra la mujer. Prevéncion. Programas de rehabilitácion, análisis internacional. Buenos Aires: BdeF, 2018.

TONELI, M. J.; BEIRAS, A.; RIED, J. Homens autores de violência contra mulheres: políticas públicas, desaios e intervenções possíveis na América Latina e Portugal. Revista de Ciências Humanas, Florianópolis, v. 51, n. 1, pp. 174-193, jan./jun. 2017. Disponível em: https://periodicos.ufsc.br/index.php/revistacfh/article/ view/2178-4582.2017v51n1p174/34480. Acesso em: 21 maio 2020.

TONELI, M. J.; BEIRAS, A.; CLIMACO, D.; LAGO, M. C. Por que pesquisar serviços destinados a homens autores de violência contra as mulheres? In: TONELI, M. J.; BEIRAS, A.; CLIMACO, D.; LAGO, M. C. Atendimento a homens autores de violência contra as mulheres: experiências latino americanas. Florianópolis: UFSC/ CFH/NUPPE, 2010. pp. 11-24.

VALA, J. Representações sociais e psicologia social do conhecimento cotidiano. In:VALA, J.; MONTEIRO, M. B. Psicologia social. 5 ed. Lisboa: Fundação Calouste Gulbekian, 2002. pp. 457-502.

VELOSO, F. G.; NATIVIDADE, C. Metodologias de abordagem dos homens autores de violência contra as mulheres. In: LOPES, P. V.; LEITE, F. Atendimento a homens autores de violência doméstica: desafios à política pública. Rio de Janeiro: Instituto de Estudos da Religião, 2013. pp. 45-64.

WORLD HEALTH ORGANIZATION (WHO). Global and regional estimates of violence against women: prevalence and health effects of intimate partner violence and non-partner sexual violence. Genebra: WHO, 2013. Disponível em: https://apps.who.int/iris/bitstream/handle/10665/85239/9789241564625_eng.pdf; jsessionid=29F28A24D42985B20FABE4F77D19275E?sequence=1. Acesso em: 16 maio 2020. 
Para publicar na revista Brasileira de Políticas Públicas, acesse o endereço eletrônico www.rbpp.uniceub.br

Observe as normas de publicação, para facilitar e agilizar o trabalho de edição. 